\title{
High-Spatial-Multiplicity Multicore Fibers for Future Dense Space-Division-Multiplexing
} Systems

Matsuo, Shoichiro; Takenaga, Katsuhiro; Sasaki, Yusuke; Amma, Yoshimichi; Saito, Shota; Saitoh, Kunimasa; Matsui, Takashi; Nakajima, Kazuhide; Mizuno, Takayuki; Takara, Hidehiko

Total number of authors:

12

Published in:

Journal of Lightwave Technology

Link to article, DOI:

10.1109/JLT.2015.2508928

Publication date:

2016

Document Version

Publisher's PDF, also known as Version of record

Link back to DTU Orbit

Citation (APA):

Matsuo, S., Takenaga, K., Sasaki, Y., Amma, Y., Saito, S., Saitoh, K., Matsui, T., Nakajima, K., Mizuno, T., Takara, H., Miyamoto, Y., \& Morioka, T. (2016). High-Spatial-Multiplicity Multicore Fibers for Future Dense Space-Division-Multiplexing Systems. Journal of Lightwave Technology, 34(6), 1464-1475. https://doi.org/10.1109/JLT.2015.2508928

\section{General rights}

Copyright and moral rights for the publications made accessible in the public portal are retained by the authors and/or other copyright owners and it is a condition of accessing publications that users recognise and abide by the legal requirements associated with these rights.

- Users may download and print one copy of any publication from the public portal for the purpose of private study or research.

- You may not further distribute the material or use it for any profit-making activity or commercial gain

- You may freely distribute the URL identifying the publication in the public portal 


\title{
High-Spatial-Multiplicity Multicore Fibers for Future Dense Space-Division-Multiplexing Systems
}

\author{
Shoichiro Matsuo, Member, IEEE, Member, OSA, Katsuhiro Takenaga, Yusuke Sasaki, Yoshimichi Amma, \\ Shota Saito, Kunimasa Saitoh, Member, IEEE, Member, OSA, Takashi Matsui, Kazuhide Nakajima, Member, IEEE, \\ Takayuki Mizuno, Member, IEEE, Hidehiko Takara, Member, IEEE, Yutaka Miyamoto, Member, IEEE, \\ and Toshio Morioka, Member, IEEE, Fellow, OSA
}

(Invited Paper)

\begin{abstract}
Multicore fibers and few-mode fibers have potential application in realizing dense-space-division multiplexing systems. However, there are some tradeoff requirements for designing the fibers. In this paper, the tradeoff requirements such as spatial channel count, crosstalk, differential mode delay, and cladding diameter are discussed. Further, the design concept and transmission characteristics of high-core-count single-mode multicore fibers are discussed. A heterogeneous multicore fiber with 30 cores and quasisingle-mode multi-core fibers with 31 cores are developed.
\end{abstract}

Index Terms-Optical fiber, optical fibers communication.

\section{INTRODUCTION}

$\mathbf{S}$ PACE division multiplexing (SDM) over multicore fibers (MCFs) or few-mode fibers (FMFs) has been investigated to overcome the capacity limitation of approximately $100 \mathrm{~Tb} / \mathrm{s} /$ fiber for the existing optical communication system over a single-mode single-core fiber (SM-SCF). Many SDM transmission experiments over MCFs or FMFs have demonstrated the possibility of SDM technology for future dense SDM systems [1]-[13].

Manuscript received October 11, 2015; revised December 5, 2015; accepted December 8, 2015. Date of publication December 16, 2015; date of current version March 3, 2016. This work was supported in part by the research project on "Innovative Optical Fiber and Communication Technology for Exa-bit Era with SDM (i-Free ${ }^{2}$ )" commissioned by the National Institute of Information and Communications Technology of Japan and by the EU-Japan coordinated R\&D project on "Scalable and Flexible Optical Architecture for Reconfigurable Infrastructure" commissioned by the Ministry of Internal Affairs and Communications of Japan and EC Horizon 2020.

S. Matsuo, K. Takenaga, Y. Sasaki, Y. Amma, and S. Saito are with the Advanced Technology Laboratory, Fujikura, Ltd., Chiba 285-8550 Japan (e-mail: shoichiro.matsuo@jp.fujikura.com; katsuhiro.takenaga@jp.fujikura. com; yusuke.sasaki@jp.fujikura.com; yoshimichi.amma@jp.fujikura.com; shota.saito@jp.fujikura.com).

K. Saitoh is with the Graduate School of Information Science and Technology, Hokkaido University, Sapporo 060-0814, Japan (e-mail: ksaitoh@ist. hokudai.ac.jp).

T. Matsui and K. Nakajima are with the Access Network Service Systems Laboratories, NTT Corporation, Tsukuba 305-0805, Japan (e-mail: matsui. takashi@lab.ntt.co.jp; nakajima.kazuhide@lab.ntt.co.jp).

T. Mizuno, H. Takara, and Y. Miyamoto are with the NTT Network Innovation Laboratories, NTT Corporation, Kanagawa 239-0847, Japan (e-mail: mizuno. takayuki@lab.ntt.co.jp; h.takara@okinawa-ct.ac.jp; miyamoto.yutaka@lab.ntt. co.jp).

T. Morioka is with DTU Fotonic, Technical University of Denmark, Lyngby 2800, Denmark (e-mail: tomo@fotonik.dtu.dk).

Color versions of one or more of the figures in this paper are available online at http://ieeexplore.ieee.org.

Digital Object Identifier 10.1109/JLT.2015.2508928
A fiber for SDM is expected to involve as many spatial channels as possible under some restrictions such as cladding diameter, intercore crosstalk (XT), inner-core XT, and differential mode delay (DMD). Many types of single-mode MCFs (SM-MCFs) and FMFs have been proposed to increase core count or mode count. The maximum core count of SM-MCF was beyond 30 [14], [15]. The mode count of FMFs reached 36 (20 LP modes) [16]. Another approach is combining few modes and multiple cores: few-mode multicore fibers (FM-MCFs). Some FM-MCFs exceeded the record spatial channel count (SCC) of SM-MCFs and FMF: 36 with 3 modes $\times 12$ cores [7], [8], 72 with 6 modes $\times 12$ cores [17], 108 with 3 modes $\times 36$ cores [9], 114 with 6 modes $\times 19$ cores [10]. However, FM-MCFs should overcome both issues for SM-MCFs and FMFs simultaneously.

In this paper, we review the features of high-spatialmultiplicity MCFs [18]. At first, the current states of the SDM fiber including FMFs, SM-MCFs, and FM-MCFs are reviewed. The tradeoff relationship between multiplicity and cladding diameter, XT, and DMD is discussed. Then, two studies on SM-MCFs with high spatial multiplicity are presented. The high-spatial-multiplicity fibers are realized using heterogeneous structures or quasi-single-mode (QSM) structures, respectively. The design concept, fabrication results, and transmission performance of the fabricated fibers are presented.

\section{Spatial Multiplicity Improvement}

In this section, recent approaches regarding SDM fiber for dense SDM are presented. After defining the parameters for comparing multiplicity, the tradeoff parameters for high spatial multiplicity—cladding diameter, core-to-core XT, and DMD— are discussed.

\section{A. SCC and Spatial Efficiency (SE)}

In this study, we used the SCC, SE, and relative SE (RSE) as a measure of the spatial multiplicity of MCFs and FMFs.

$$
\begin{aligned}
\mathrm{SCC} & =\mathrm{CC} \cdot \mathrm{MC}, \\
\mathrm{SE} & =\frac{\mathrm{SCC}}{(\pi / 4) D_{\mathrm{c}}^{2}}, \\
\mathrm{RSE} & =\frac{\mathrm{SE}_{\mathrm{MCF}}}{\mathrm{SE}_{\mathrm{CSMF}}}=\mathrm{SCC} \cdot\left(\frac{125}{D_{\mathrm{c}}}\right)^{2},
\end{aligned}
$$




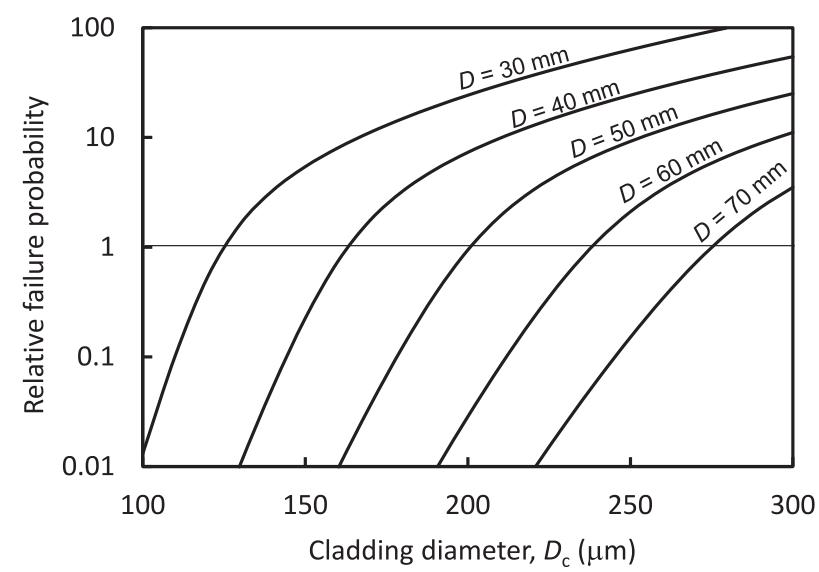

Fig. 1. Relative failure probability as a function of cladding diameter $D_{c}$ for different bending diameters $D$. Failure probability was estimated under the condition of 100 turns, 20 years, and $1 \%$ proof.

where $\mathrm{CC}$ is the core count in a fiber, $\mathrm{MC}$ is the mode count in a core, $D_{c}$ is the cladding diameter of a fiber, $\mathrm{SE}_{\mathrm{MCF}}$ is the $\mathrm{SE}$ of an $\mathrm{MCF}$, and $\mathrm{SE}_{\mathrm{CSMF}}$ is the $\mathrm{SE}$ of the conventional single-mode fiber (SMF) with $\mathrm{SCC}=1, A_{\mathrm{eff}}=80 \mu \mathrm{m}^{2}$ at $1550 \mathrm{~nm}$, and $D_{c}$ $=125 \mu \mathrm{m}$.

\section{B. SCC Versus Cladding Diameter}

The cladding diameter of most MCFs presented so far is larger than $125 \mu \mathrm{m}$, which is the general cladding diameter of SM-SCFs. However, the cladding diameter of MCFs is limited to less than a certain value based on the requirements of the transmission fiber.

The first limiting factor is mechanical reliability. Fig. 1 shows the simulation results of failure probability as a function of the cladding diameter for a different bending diameter $D$ under the condition of 100 turns, 20 years, and 1\% proof [19]. Relative failure probability is the failure probability of a fiber with a certain $D_{c}$ to the failure probability of a fiber with $D_{c}=125 \mu \mathrm{m}$ and $D=30 \mathrm{~mm}$. Here, we define the $D$ at which the relative failure probability equals 1 as the allowable bending diameter for a $D_{c}$. The allowable bending diameter increases following an increase in the $D_{c}$. We should accept an allowable bending diameter larger than $60 \mathrm{~mm}$ if the $D_{c}$ exceeds approximately $250 \mu \mathrm{m}$.

The allowable bending diameter can be improved by using a heightened proof level. Fig. 2 shows the relationship between the allowable bending diameter and the proof level for various $D_{c} \mathrm{~s}$. Even for a fiber with $D_{c}=300 \mu \mathrm{m}$, the allowable bending diameter can be reduced to less than $60 \mathrm{~mm}$ for a proof level larger than $1.5 \%$. Note that the required stress for a proof test is proportional to $D_{c}{ }^{2}$ and the proof level. The possibility of high-level proof testing for a large cladding diameter fiber may limit the possible $D_{c}$.

Another limiting factor is splice ability. A large cladding diameter implies that the position of the outermost core is far away from the center of the cladding. The splice loss $\left(L_{s}\right.$ in $[\mathrm{dB}]$ ) is given by the following equation [20]:

$$
L_{\mathrm{S}}=-10 \log \left(\left(\frac{2 w_{1} w_{2}}{w_{1}^{2}+w_{2}^{2}}\right)^{2} \exp \left(-\frac{2 d^{2}}{w_{1}^{2}+w_{2}^{2}}\right)\right),
$$

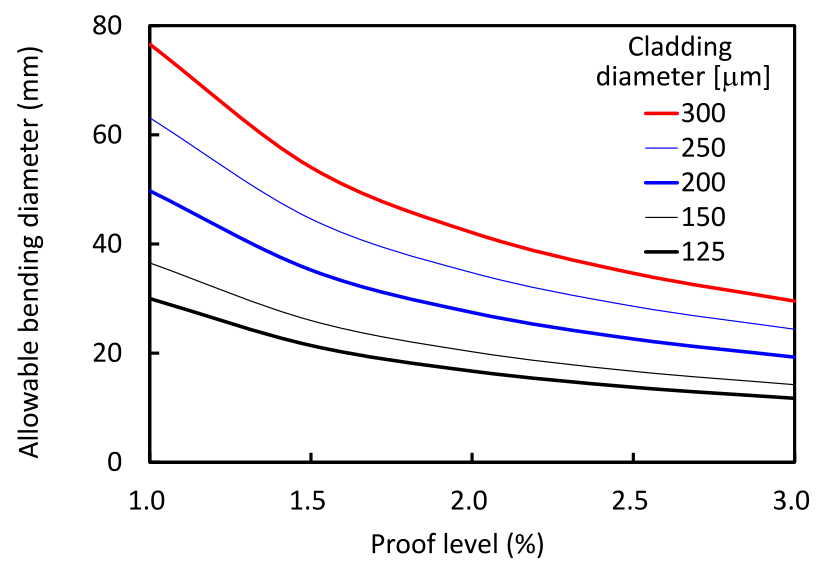

Fig. 2. Allowable bending diameter as a function of proof level for various cladding diameters.

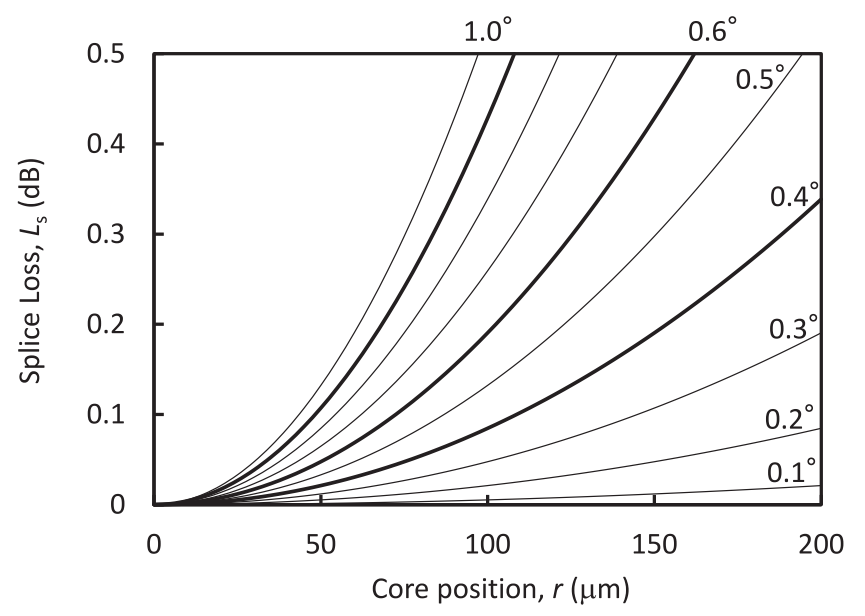

Fig. 3. Calculated splice loss as a function of core position for various angle alignment errors.

where $2 w_{1}$ and $2 w_{2}$ are the mode field diameters of the spliced fibers and $d$ is the offset of the core centers of the spliced fibers. If fibers whose cores are positioned at $r$ from the center of a cladding are aligned with the angle error $\theta, d$ is given by

$$
d=2 r \sin (\theta / 2) .
$$

Fig. 3 shows the estimated splice losses as a function of core position for different angle alignment errors according to (4) and (5). Both $2 w_{1}$ and $2 w_{2}$ are $10 \mu \mathrm{m}$. As the distance from the center of the cladding increase, excess splice loss due to errors in angle alignment is increased. Reference [21] reported that the averaged, maximum, and minimum angle alignment error was $0.6^{\circ}, 0.9^{\circ}$, and $0.4^{\circ}$ for a commercially available fusion splicer that aligns cores with fiber-rotation and end-view functions [22]. A large $r$ requires a small angle alignment error for realizing a small splice loss. The $r$ will be limited to approximately $75 \mu \mathrm{m}$ to achieve an averaged splice loss $<0.1 \mathrm{~dB}$ for the current fusion splicer. The limit may be relaxed owing to the improvement of alignment accuracy and the enlargement of the mode field diameter of the spliced fiber. For fibers with $2 w_{1}=2 w_{2}=$ $12 \mu \mathrm{m}$, whose effective area is larger than $110 \mu \mathrm{m}^{2}$, the $r$ for achieving the splice loss $<0.1 \mathrm{~dB}$ is increased to approximately $85 \mu \mathrm{m}$. However, the increased effective area is not preferable 


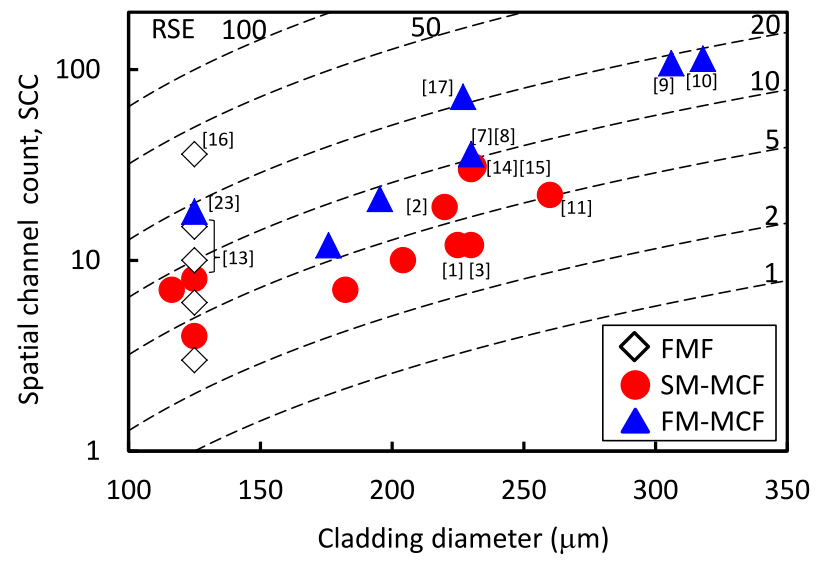

Fig. 4. SCC as a function of cladding diameter for FMFs (open lozenge symbols), SM-MCFs (red solid circle symbols), and FM-MCFs (Blue triangle symbols). Contour lines are RSE.

for reducing XT. Accordingly, the splice ability may become a limiting factor for the $D_{c}$.

Fig. 4 shows the SCC of recently proposed MCFs and FMFs as a function of cladding diameter. The contour lines indicate the RSE.

The cladding diameter of almost all FMFs presented so far was $125 \mu \mathrm{m}$. The SCC, i.e., the mode count for an FMF with $125-\mu \mathrm{m}$ cladding diameter, and RSE reached the value of 36 [16], [27]. However, the DMD becomes considerably sensitive against structural parameter fluctuations that depend on the increase in SCC [16], [27]. The required DMD level for realistic signal processing is a limiting factor for the SCC of the FMFs.

At this time, the maximum SCC of SM-MCFs is over 30. An MCF with 30 cores employed a heterogeneous core structure to realize high core count and low XT simultaneously [14]. The fiber contained 30 cores with $A_{\text {eff }}$ of $80 \mu \mathrm{m}^{2}$ in a $230-\mu \mathrm{m}$ cladding, and it marked an RSE of 8.9. An MCF with 31 cores employed QSM design [15]. The RSE of the 31-core fiber was 9.1, which is the highest value of the SM-MCF.

Another approach for improving spatial multiplicity is using the FM-MCF. The FM-MCFs investigated so far can be categorized into three groups. The first group includes a fiber with a cladding diameter of $125 \mu \mathrm{m}$ [23]. The fiber exhibited an SCC of 18 and RSE of 18. The second group focuses on improving the SCC [9], [10]. Two fibers recorded an SCC larger than 100 and RSE of approximately 18 . However, their cladding diameter exceeded $300 \mu \mathrm{m}$. The validity of such large cladding diameters in terms of mechanical reliability and splicing needs to be further analyzed. The last group aims to maximize the SCC and RSE under a moderate cladding diameter smaller than $250 \mu \mathrm{m}$. A three-mode (two LP modes) 12-core fiber with a cladding diameter of $230 \mu \mathrm{m}$ exhibited an SCC of 36 and RSE of 10.64 . Another example is a six-mode (four LP modes) 12-core fiber with a cladding diameter of $227 \mu \mathrm{m}$. This fiber exhibited an SCC of 72 and RSE of 21.83, which is the highest RSE for MCFs presented so far.

\section{SCC Versus Core-to-Core XT}

$\mathrm{XT}$ is an important parameter to compare the performance of MCFs. XT limits the transmission distance, transmission

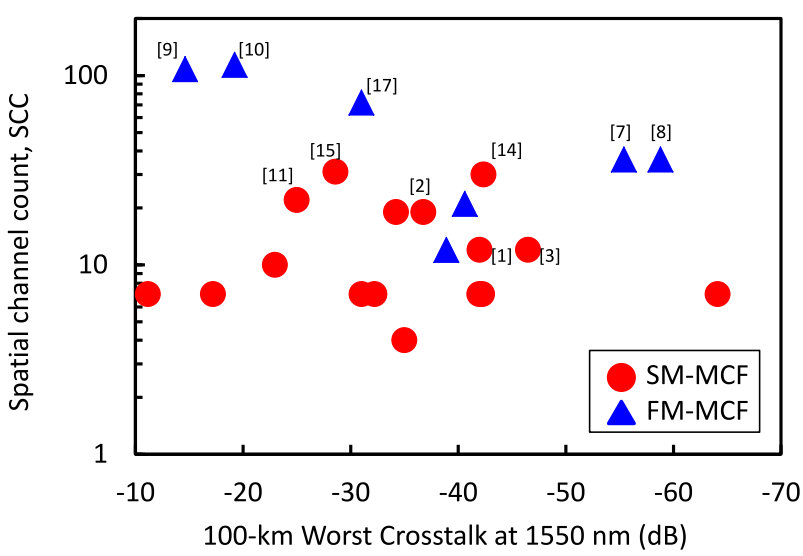

Fig. 5. SCC as a function of $100-\mathrm{km}$ worst XT at $1550 \mathrm{~nm}$ for MCFs presented so far.

capacity, and modulation format [24]. Fig. 5 indicates the relationship between SCC and XT for the presented MCFs. We employed the XT between the highest order modes as the XT of FM-MCFs because the XT between the highest order modes is larger than the XT among other combination of modes [25]. MCFs with low XT $<-40 \mathrm{~dB} / 100 \mathrm{~km}$ have contributed to achieve some remarkable transmission: a 12-core fiber with ring structure for $1 \mathrm{Pbit} / \mathrm{s} /$ fiber transmission with 32QAM [1], a 12-core fiber with a dual-ring structure for $1 \mathrm{Ebit} / \mathrm{s} \mathrm{km}$ transmission with 16QAM [3], a 7-core fiber with hexagonal closed pack structure for $1 \mathrm{Ebit} / \mathrm{s} \mathrm{km}$ transmission over transoceanic distance [4], and an FM-MCF with a square lattice structure for dense SDM of 36 SCC over $527 \mathrm{~km}$ [8].

Recently proposed SM-MCFs with SCC of 30 and more [14], [15] and FM-MCF with SCC of 72 [17] showed XT of about $-30 \mathrm{~dB} / 100 \mathrm{~km}$. These fibers will contribute to transmission with large capacity or high-order modulation.

The combination of SCC and XT is affected by $A_{\text {eff }}$ and the cladding diameter [26]. With regard to a long-haul system, an MCF with large $A_{\text {eff }}$ and small XT is required. This requirement limits the SCC. The possible SCC will be determined by the requirement on $A_{\text {eff }}$ and XT from the transmission system.

\section{SCC Versus DMD}

In the case of FMFs and FM-MCFs, DMD, which is the time difference between the fastest mode and the slowest mode in a core, is a very important parameter because a large DMD requires heavy signal processing for recovering mode-coupled signals. Fig. 6 shows the relationship between the maximum |DMD| and SCC of FMFs and FM-MCFs. References [16] and [25] suggest that DMD control becomes very difficult as the mode count become large. The |DMD| of FMFs whose mode count is larger than 10 ranged at a few hundred ps $/ \mathrm{km}$. A multistep profile and a graded index profile are useful to reduce |DMD| and control DMD characteristics [16], [27], [28]. The DMD characteristics of fabricated fibers also depend on the fabrication process of the fiber. The process such as modified chemical vapor deposition (MCVD) is preferable to control index profiles precisely. 


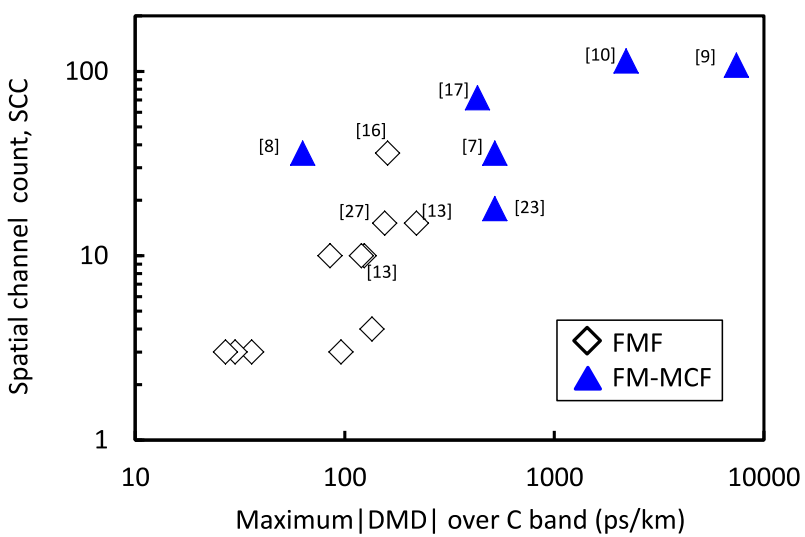

Fig. 6. SCC as a function of measured maximum DMD over the $\mathrm{C}$ band. Some data were the $|\mathrm{DMD}|$ at $1550 \mathrm{~nm}$.

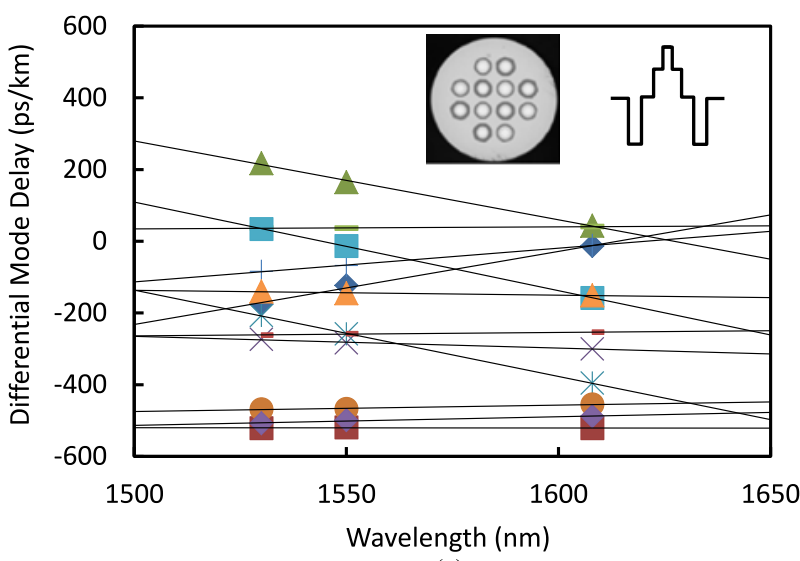

(a)

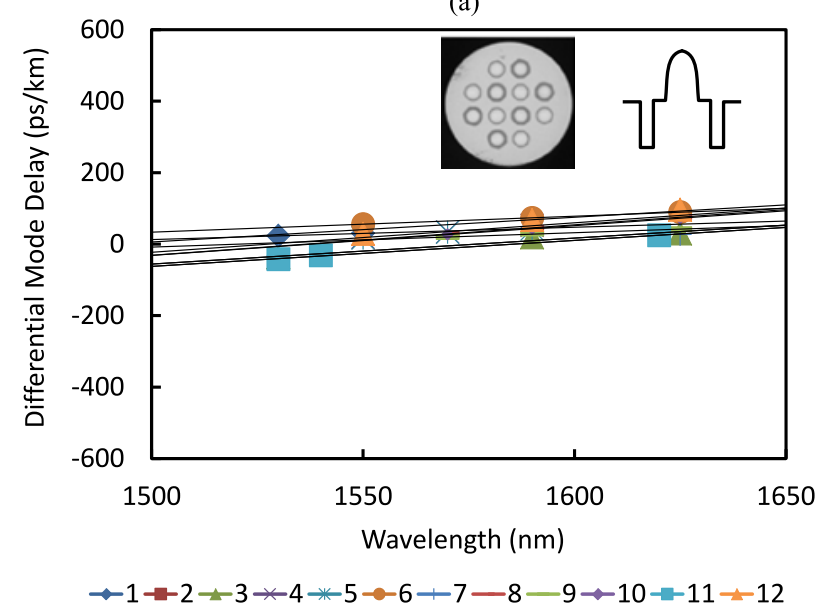

(b)

Fig. 7. Measured wavelength dependence of the DMD for two kinds of FMMCFs with 36 spatial channels [18], [29]: (a) A fiber with a multi-step index profile [7]. (b) A fiber with a graded index profile [8]. Symbols indicate the measured DMD. Lines indicate a linear approximation of the measured data.

FM-MCFs require suppressing $|\mathrm{DMD}|$ for all cores within a certain range. The $|\mathrm{DMD}|$ of the FM-MCFs with SCC larger than 100 was greater than $1000 \mathrm{ps} / \mathrm{km}$ [9], [10]. The |DMD| over the C band of the FM-MCFs with SCC of 36 was drastically reduced from 530 to $63 \mathrm{ps} / \mathrm{km}$ as shown in Fig. 7 [18], [29]. The fiber in Fig. 7(a) had cores with a multistep profile and was fabricated by the vapor-phase axial deposition method. The fiber in Fig. 7(b) had cores with a graded-index profile and

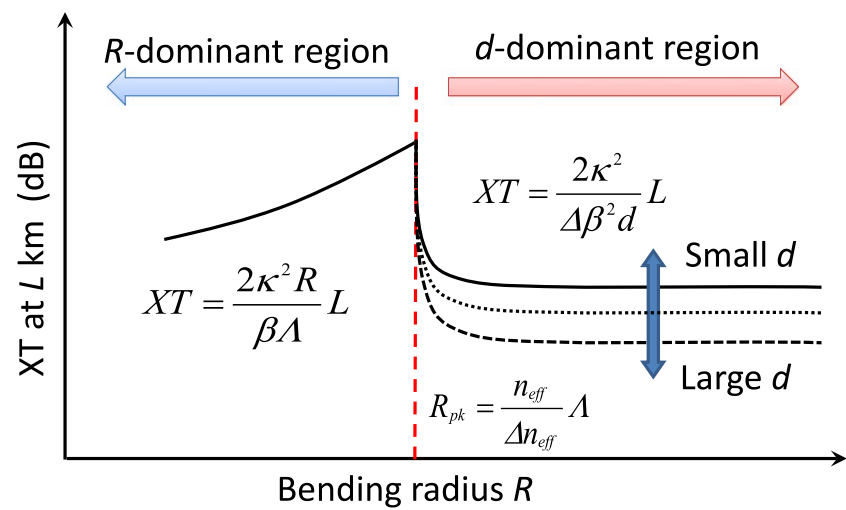

Fig. 8. Schematic of the dependence of bending radius $R$ on XT.

was fabricated by the MCVD method. The combination of the change of index profile and fabrication process realized DMD reduction. The reduction of |DMD| enables the lengthening of the transmission distance from 40.4 [7] to $527 \mathrm{~km}$ [8]. The FMMCF with SCC of 72, which involves 12 cores with six modes (four LP modes), successfully controlled |DMD| under less than $430 \mathrm{ps} / \mathrm{km}$ for all cores owing to a graded index profile [17]. We need to select the combination of $\mathrm{CC}$ and $\mathrm{MC}$ with the tradeoff relationship between SCC and DMD in mind.

\section{Single-Mode 30-Core Fiber With HeTEROGENEOUS CORE DESIGN}

\section{A. Fiber Design}

Heterogeneous core design means that the effective indices $\left(n_{\mathrm{eff}} \mathrm{s}\right)$ are different for all adjacent cores [30]. If the $n_{\mathrm{eff}} \mathrm{s}$ of the adjacent cores are different, the XT between the cores drastically changes at a certain bending radius $\left(R_{\mathrm{pk}}\right)$ [31], as shown in Fig. 8. $R_{\mathrm{pk}}$ is given by

$$
R_{\mathrm{pk}}=\frac{n_{\mathrm{eff}}}{\Delta n_{\mathrm{eff}}} \Lambda
$$

where $n_{\text {eff }}$ is the effective index of a propagation mode, $\Delta n_{\mathrm{eff}}$ is the effective index difference between cores, and $\Lambda$ is the core pitch. If the bending radius $R$ is less than $R_{\mathrm{pk}}$, XT is given by the following equation [31].

$$
\mathrm{XT}=\frac{2 \kappa^{2} R}{\beta \Lambda} L
$$

where $k$ is the coupling coefficient, $\beta$ is the propagation constant, and $L$ is the length of a fiber. In this case, XT varies with bending radius $R$. Accordingly, we can call this region the $R$-dominant region. In contrast, if the bending radius $R$ is larger than $R_{\mathrm{pk}}$, $\mathrm{XT}$ is given by the following equation [32]:

$$
\mathrm{XT}=\frac{2 \kappa^{2}}{\Delta \beta^{2} d} L
$$

where $d$ is the correlation length. In this case, the XT of the region varies with $d$ and we consider this region $d$-dominant. The XT over the $d$-dominant region is smaller than that over the $R$-dominant region. By setting the $R_{\mathrm{pk}}$ value below the effective bending diameter in cables, we can reduce the XT of an MCF and maximize the number of cores within a limited range of 


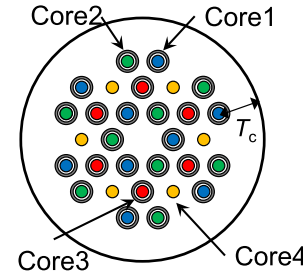

(a)

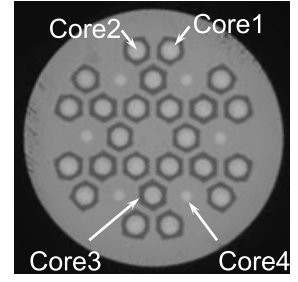

(b)

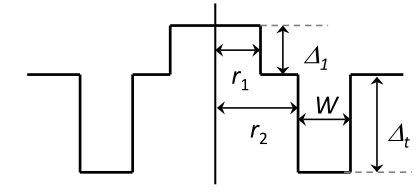

Trench-assisted profile(Core 1, 2, 3)

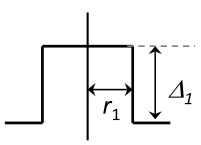

Step-index profile(Core 4) (c)

Fig. 9. A heterogeneous SM-MCFs with 30 cores [14], [28]: (a) A schematic of the fiber structure. (b) A cross-sectional view of a fabricated fiber. (c) Index profiles of the cores.

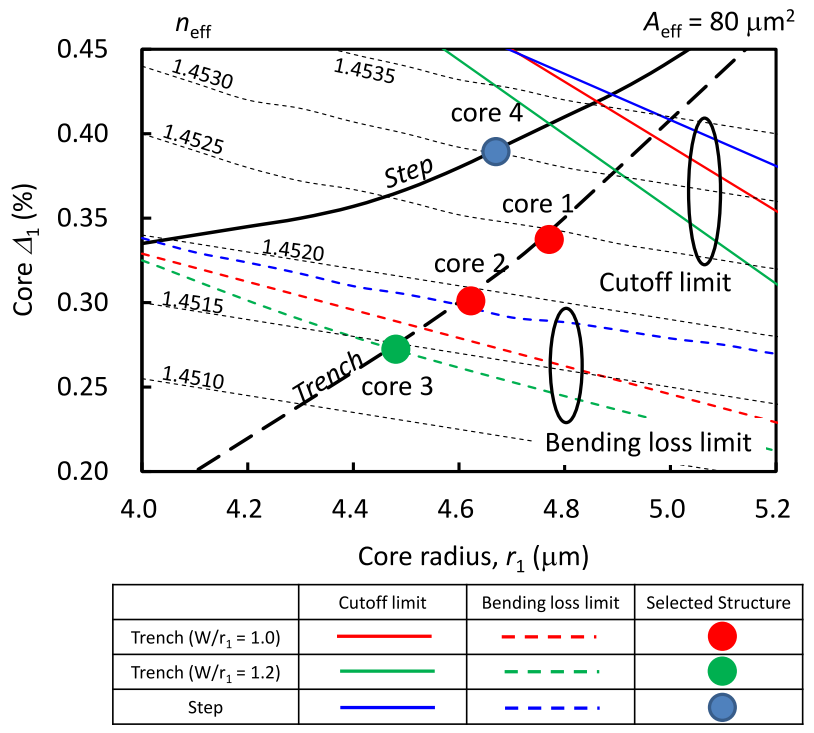

Fig. 10. Relationship between the core parameters and effective indices in trench-assisted and step-index cores for a 30-core fiber [14], [18], [29].

cladding diameters. However, the different $n_{\text {eff }}$ design has the tendency to produce different $A_{\text {eff }}$ values, which is not desirable for realizing homogeneity of transmission characteristics and low splice loss.

The same $A_{\text {eff }}$ for all the cores with heterogeneous $n_{\text {eff }}$ is achievable through the careful selection of core parameters such as the core radius $(r)$ and relative index difference $(\Delta)$ [33], [34]. However, the same $A_{\text {eff }}$ with heterogeneous $n_{\text {eff }}$ design limits the range of core parameters to ensure the single-mode condition and reduce the bending loss of the fundamental mode [33].

Fig. 9 shows the schematic structure and cross-sectional view of a fabricated heterogeneous SM-MCF with 30 cores. $T_{c}$ is the outer cladding thickness, which is the distance between the center of an outermost core and the edge of a cladding. Fig. 10 shows the simulation results for fiber core design [14], [18], [29]. The lines of the cutoff limit and bending loss limit were calculated for each structure. The lines of $n_{\text {eff }}$ were drawn for the trench-assisted structure. The structure of the fiber was based
TABLE I

Simulation Results for a Heterogeneous 30-Core Fiber

\begin{tabular}{lccccc}
\hline \hline Core Type & $r_{1}[\mu \mathrm{m}]$ & $\Delta_{1}[\%]$ & $r_{2} / r_{1}$ & $W / r_{1}$ & $A_{\text {eff }}{ }^{2)}\left[\mu \mathrm{m}^{2}\right]$ \\
\hline Core 1 $^{1)}$ & 4.76 & 0.338 & 1.7 & 1.0 & 80.2 \\
Core 2 $^{1)}$ & 4.62 & 0.305 & 1.7 & 1.0 & 80.3 \\
Core 3 $^{1)}$ & 4.47 & 0.273 & 1.7 & 1.2 & 80.2 \\
Core 4 & 4.68 & 0.388 & - & - & 80.0 \\
\hline \hline
\end{tabular}

\begin{tabular}{lcc}
\hline \hline Combination & $\Delta n_{\mathrm{eff}}{ }^{2)}$ & $R_{\mathrm{p} \mathrm{k}}{ }^{3)}[\mathrm{mm}]$ \\
\hline Core 1-2 & 0.00051 & 86 \\
Core 1-3 & 0.00100 & 44 \\
Core 1-4 & 0.00063 & 69 \\
Core 2-3 & 0.00050 & 88 \\
Core 2-4 & 0.00113 & 38 \\
Core 3-4 & 0.00163 & 27 \\
\hline \hline & \\
1) $\Delta_{\mathrm{t}}=-0.7 \%$. & \\
2) Calculated wavelength $=1550 \mathrm{~nm}$. & \\
3) Core pitch, $\Lambda=30 \mu \mathrm{m}$.
\end{tabular}

on a hexagonal closed-pack structure with 37 cores. The six outermost cores were removed to reduce the cladding diameter. The central core was also removed because wavelength lengthening of the core due to the trench-assisted structure was unavoidable [35]. Four kinds of cores were used to produce a heterogeneous relation for all adjacent cores under the limitation of using the same $A_{\text {eff }}$ for all cores. Core 1, 2, and 3 employed a trenchassisted structure to reduce the XT. Core 4 had no trench layer to avoid the cutoff wavelength lengthening of the inner cores. Table I summarizes the core parameters derived from Fig. 10. The $\Delta n_{\text {eff }} \mathrm{S}$ were larger than 0.0005 for all combinations. The $\Delta n_{\text {eff }}$ s ensured that the $R_{\mathrm{pk}}$ was less than $100 \mathrm{~mm}$ for a $\Lambda$ of $30 \mu \mathrm{m}$. If we set the cladding diameter at $230 \mu \mathrm{m}$, the $T_{c}$ will be $35.6 \mu \mathrm{m}$, which is sufficient for reducing the excess loss due to a high-index coating [35].

\section{B. Characteristics of a Fabricated Fiber}

Fig. 9(b) shows a cross sectional view of a fabricated 30-core fiber. We fabricated 9.6-km fiber with a $D_{c}$ of $228 \mu \mathrm{m}$ and $\Lambda$ of $29.7 \mu \mathrm{m}$ using the stack and draw method. The averaged attenuation and averaged $A_{\text {eff }}$ at $1550 \mathrm{~nm}$ were $0.50 \mathrm{~dB} / \mathrm{km}$ and $77.3 \mu \mathrm{m}^{2}$, respectively. The high attenuation was caused by problems in the process during stacking. The cable cutoff wavelengths were less than $1.57 \mu \mathrm{m}$, which was larger than the designed value of less than $1.53 \mu \mathrm{m}$. The lengthening of the cutoff wavelength originated from the profile difference between the simulation and fabricated fiber. Fig. 11 shows the measured XT of a 9.6-km fiber wound on a spool with a diameter of $310 \mathrm{~mm}$. We evaluated the XT using statistical measurements by sweeping the wavelength [35]. A single-core fiber with a trench structure was used as the incident and receiving fiber to improve the dynamic range of XT [36], which was about $80 \mathrm{~dB}$ for our set-up. The measured XT for the 9.6-km fiber was, on average, less than $-55 \mathrm{~dB}$ for all kinds of combinations.

We also measured the XT for a 22-m fiber to confirm the $R_{\mathrm{pk}}$ of the fabricated fiber, as shown in Fig. 12. The solid symbols 


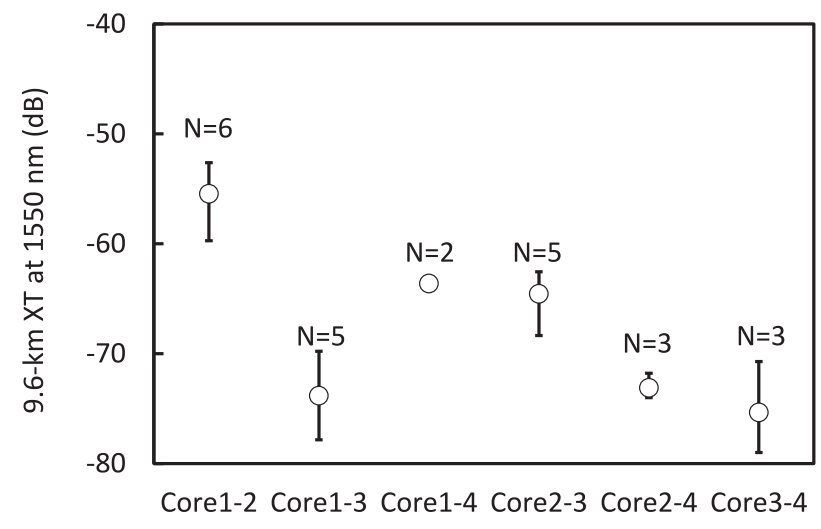

Fig. 11. Measured XT at $1550 \mathrm{~nm}$ for a $9.6-\mathrm{km}$ fiber. Core $i-j$ means the XT between core $i$ and core $j$. $N$ indicates the number of measurements for core $\mathrm{i}-\mathrm{j}$.

indicate the measured XT and the solid lines show the calculated $\mathrm{XT}$ for different $d$ values. We measured the XT of the freely coiled fiber at $R=140,70$, and $35 \mathrm{~mm}$. The measurement limit for XT in our system was about $-70 \mathrm{~dB}$. The results indicate that, as designed, the $R_{\mathrm{pk}}$ of the fabricated fiber was around $100 \mathrm{~mm}$. The measured XTs for bending radii $<R_{\mathrm{pk}}$ agree well with the simulation results. However, the measured XTs for bending radii $>R_{\mathrm{pk}}$ were smaller than the XT estimated with $d=50 \mathrm{~mm}$, which was reported in [34]. We were not able to evaluate $d$ from the measured results because the results were smaller than the measurement limit. Further study is required for XT simulation of a heterogeneous MCF.

\section{Single-Mode 31-Core Fiber With QSM CoRE Design}

As demonstrated in the previous section, a heterogeneous core is quite effective for reducing XT. However, precise process control of the core structure is required for preparing heterogeneous cores. In this section, we demonstrate a high-core-count MCF with homogeneous structure.

\section{A. Fiber Design}

As shown in Fig. 5, the FM-MCF concept is helpful for realizing large SCC and small XT simultaneously. However, heavy signal processing is required to recover the distorted signal due to mode coupling. QSM transmission is a technique that uses only the fundamental mode of an FMF. We are able to get the freedom for fiber design by lengthening the cutoff wavelength with QSM design. In the case of QSM design for a conventional single-core fiber, we used the freedom to enlarge the $A_{\text {eff }}$. QSM transmission experiments over the FMFs have been successfully demonstrated [37]. The advantage of QSM transmission is the reduction of the nonlinearity of transmission lines owing to the enlarged $A_{\text {eff }}$ of the fundamental mode of FMFs. However, in the case of MCF design, we used the freedom to strengthen the confinement of the fundamental mode instead of $A_{\text {eff }}$ enlargement. An advantage of applying QSM transmission to $\mathrm{MCF}$ designs is the XT reduction owing to the high confinement of the $\mathrm{LP}_{01}$ mode in a few-mode core. The suppression of XT enables a dense core arrangement within a limited range of cladding diameters. It has been reported that the undesired
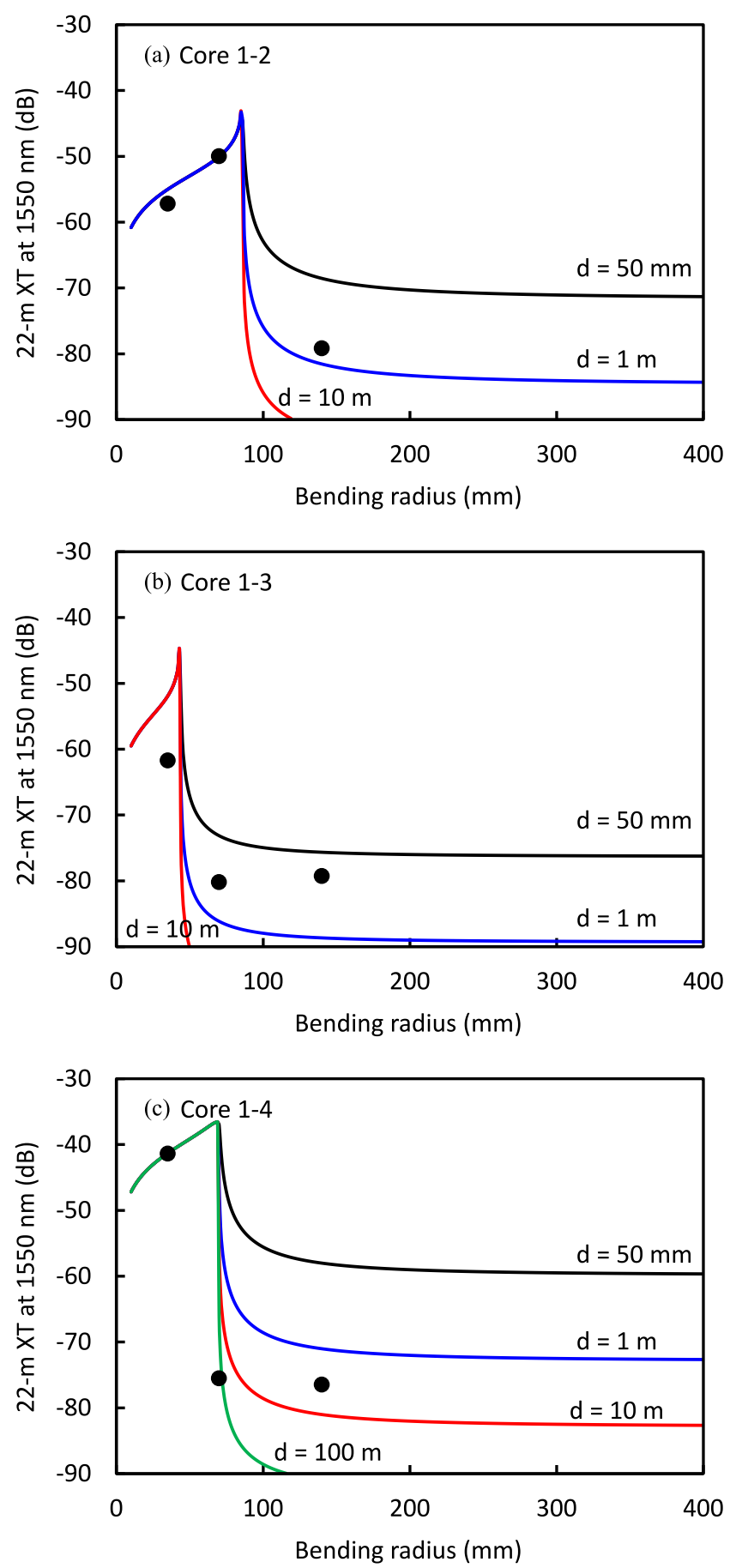

Fig. 12. Measured and simulated XT at $1550 \mathrm{~nm}$ for a 22-m fiber. Core $i-j$ means the XT between core $i$ and core $j . N$ indicates the number of measurements for core $i-j$. The solid symbols are measured results. The lines indicate the simulated XT with a correlation length of $50 \mathrm{~mm}$.

remaining $\mathrm{LP}_{11}$ mode, which is generated during signal propagation through fibers and at splice points, deteriorates the quality of $\mathrm{LP}_{01}$-mode signals [37], [38]. The intentional elimination of the $\mathrm{LP}_{11}$ mode is helpful in reducing signal deterioration.

In the case of the MCFs, the propagating power in the outermost cores can be absorbed into a coating with a low outer cladding thickness $\left(T_{c}\right)$. In general, the field size of an $\mathrm{LP}_{11}$ mode is far larger than that of an $\mathrm{LP}_{01}$ mode. Accordingly, an 
TABLE II

CORE PARAMETERS FOR SIMULATION

\begin{tabular}{lcccc}
\hline \hline ID & $\Delta[\%]$ & $r_{1}[\mu \mathrm{m}]$ & $r_{2} / r_{1}$ & $W / r_{1}$ \\
\hline Design 1 & 0.45 & 86 & 1.7 & 0.8 \\
Design 2 & 0.45 & 38 & 1.7 & 0.9 \\
Design 3 & 0.45 & 27 & 1.7 & 1.0 \\
\hline \hline
\end{tabular}

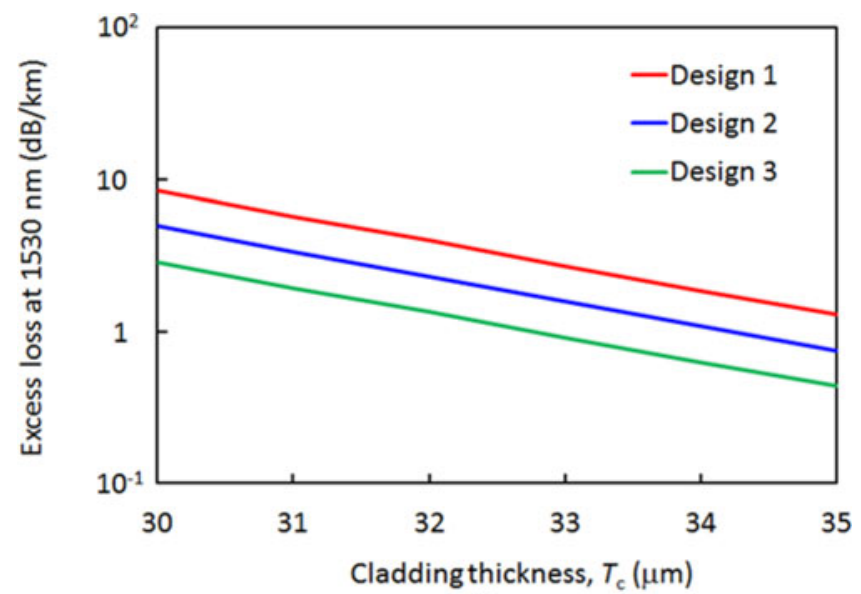

(a)

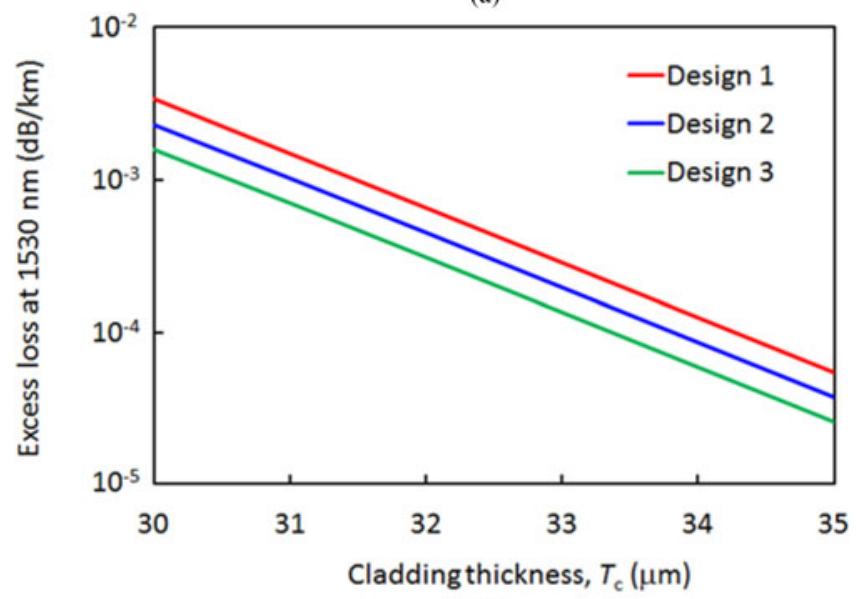

(b)

Fig. 13. Calculated excessive losses as a function of outer cladding thickness $\left(T_{c}\right)$ for the cores shown in Table II, (a) $\mathrm{LP}_{11}$ mode, (b) $\mathrm{LP}_{01}$ mode.

optimized $T_{c}$ helps realize the coexistence of the large excessive loss of an $\mathrm{LP}_{11}$ mode and the negligible excessive loss of an $\mathrm{LP}_{01}$ mode in the outermost cores. The direct coating absorption of the inner cores is far smaller than that of the outermost cores. However, the power of an $\mathrm{LP}_{11}$ mode is expected to leak to a coating through the XT from the inner cores to the outer cores.

We designed a QSM MCF using the above concepts. The fiber contains 31 trench-assisted homogeneous cores in a hexagonal close-packed structure with a cladding diameter of $230 \mu \mathrm{m}$ [15]. The $A_{\text {eff }}$ at $1550 \mathrm{~nm}$ was set as $80 \mu \mathrm{m}^{2}$, which is the same as that of a conventional SMF. A trench-assisted structure, which is shown in Fig. 9(c), was used for all cores. We optimized the core parameters and $T_{c}$ by simulation. Table II summarizes the core parameters used in the simulation and $\Delta_{\mathrm{t}}=-0.7 \%$. Fig. 13 shows the calculated excessive loss of the $\mathrm{LP}_{11}$ mode at $1530 \mathrm{~nm}$

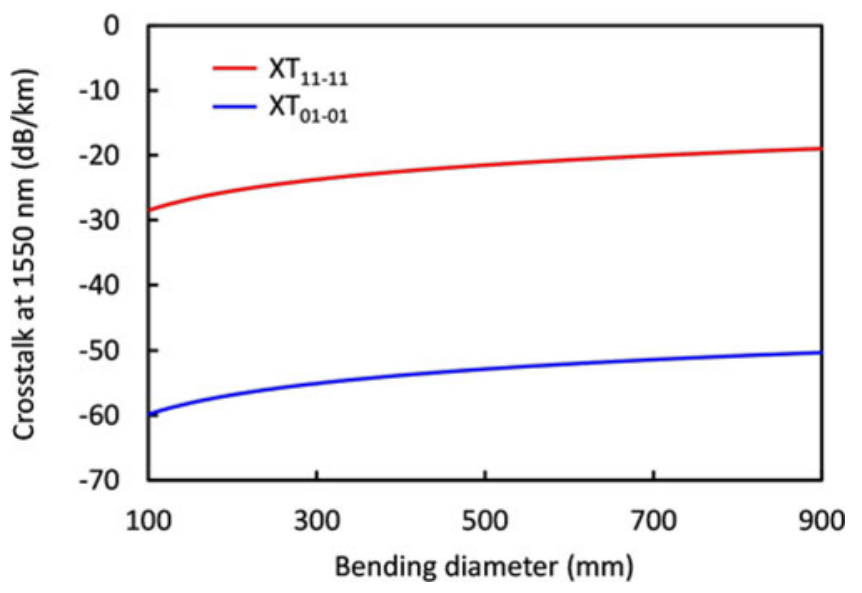

Fig. 14. Calculated core-to-core XT for the same mode in cores at $1550 \mathrm{~nm}$ as a function of bending diameter.

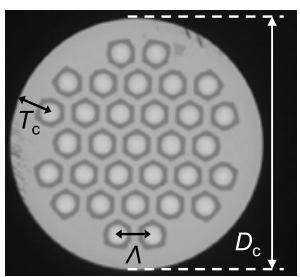

(a)

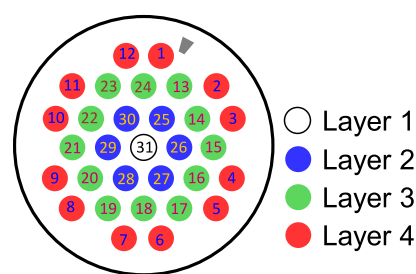

(b)
Fig. 15. A fabricated QSM 31-core fiber: (a) A cross-sectional view. (b) The definition of the layer and core numbers.

and the $\mathrm{LP}_{01}$ mode at $1625 \mathrm{~nm}$ due to absorption into the coating as a function of $T_{c}$ with a bending diameter of $280 \mathrm{~mm}$. We employed an $\mathrm{LP}_{01}$-excessive-loss of $0.001 \mathrm{~dB} / \mathrm{km}$ as a reference. Design 1 requires a relatively large $T_{c}$ to realize the employed $\mathrm{LP}_{01}$-excessive-loss. Design 3 shows a small $\mathrm{LP}_{11}$-excessiveloss for an $\mathrm{LP}_{01}$-excessive-loss of $0.001 \mathrm{~dB} / \mathrm{km}$. Design 2 is a well-balanced design that achieves an $\mathrm{LP}_{11}$-excessive-loss greater than $3 \mathrm{~dB} / \mathrm{km}$ and an $\mathrm{LP}_{01}$-excessive-loss smaller than $0.001 \mathrm{~dB} / \mathrm{km}$ at a $T_{c}$ of about $31 \mu \mathrm{m}$. Fig. 14 shows the calculated core-to-core $\mathrm{XT}$ at $1550 \mathrm{~nm}$ between the $\mathrm{LP}_{11}$ modes $\left(\mathrm{XT}_{11-11}\right)$ and between the $\mathrm{LP}_{01}$ modes $\left(\mathrm{XT}_{01-01}\right)$ as a function of the bending diameter for a core pitch $(\Lambda)$ of $32 \mu \mathrm{m}$. XT $\mathrm{XT}_{01-01}$ less than $-46 \mathrm{~dB} / \mathrm{km}$, which leads to XT of $-19 \mathrm{~dB}$ after $500-\mathrm{km}$ transmission, is satisfied under a bending diameter of several hundred millimeters. The large XT enables QPSK transmission over $500 \mathrm{~km}$ with a Q-penalty of $0.5 \mathrm{~dB}$ [24], [39]. $\mathrm{XT}_{11-11}$ exceeds $\mathrm{XT}_{01-01}$ by more than $30 \mathrm{~dB}$. This is helpful for transferring the power of the $\mathrm{LP}_{11}$ mode in the inner cores to the outermost cores, where the power of the $\mathrm{LP}_{11}$ mode is expected to be absorbed into the coating.

\section{B. Characteristics of the Fabricated Fiber}

We fabricated a homogeneous QSM 31-core fiber based on design 2 [15]. Fig. 15 shows a cross section and the layer/core assignments of the fiber. $\Lambda, T_{c}$, and $D_{c}$ of the fabricated fiber was 31.6, 31.5, and $231 \mu \mathrm{m}$, respectively. Table III summarizes the averaged optical characteristics of some cores in each layer. 
TABLE III

MEASURED CHARACTERISTICS OF A FABRICATED FIBER

\begin{tabular}{lcccc}
\hline \hline & Layer 1 & Layer 2 & Layer 3 & Layer 4 \\
\hline$A_{\mathrm{eff}}{ }^{*}\left[\mu \mathrm{m}^{2}\right]$ & 75.0 & 75.0 & 74.4 & 75.3 \\
$\lambda_{\mathrm{cc}}[\mu \mathrm{m}]$ & 2.04 & 1.95 & 1.89 & 1.68 \\
\hline \hline
\end{tabular}

$A_{\mathrm{eff}}^{*}$ of the fundamental mode measured at $1550 \mathrm{~nm}$.

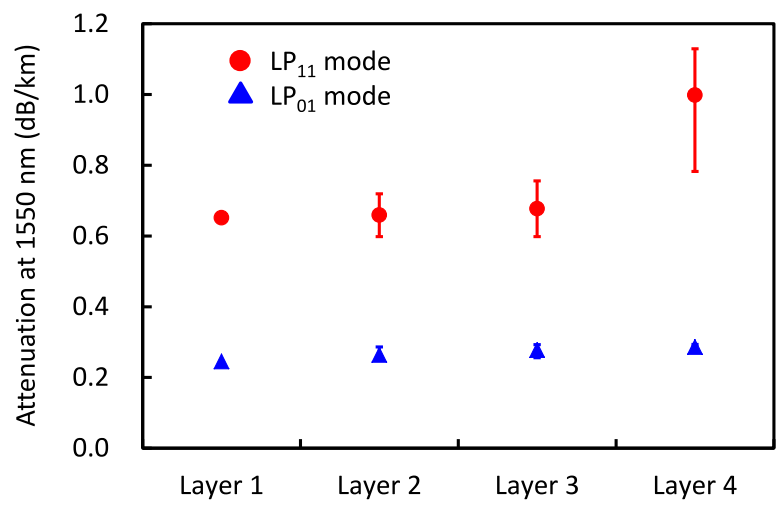

Fig. 16. Measured attenuation of the $\mathrm{LP}_{01}$ and $\mathrm{LP}_{11}$ modes at $1550 \mathrm{~nm}$. The red circles and blue triangle symbols are the average attenuation of each layer. The bars indicate the maximum and minimum value of each layer.

The cable cutoff wavelengths $\left(\lambda_{c c} s\right)$ of the inner cores were far longer than those of the outer cores owing to the existence of outer trench-assisted cores [35].

Fig. 16 shows the measured attenuation of each mode. The attenuation of the $\mathrm{LP}_{11}$ mode, particularly in layer 4 , was far larger than that of the $\mathrm{LP}_{01}$ mode. This indicates that the power of the $\mathrm{LP}_{11}$ mode was conspicuously absorbed into the coating. The measured attenuation $\left(\alpha_{\text {total }}\right)$ of a core is given by the following equation:

$$
\alpha_{\text {total }}=\alpha_{\text {pro }}+\alpha_{\mathrm{XT}}+\alpha_{\mathrm{ex}},
$$

where $\alpha_{\mathrm{pro}}$ is the loss without the influence of absorption and $\mathrm{XT}, \alpha_{\mathrm{XT}}$ is the loss due to XT, and $\alpha_{\mathrm{ex}}$ is the excessive loss due to the coating. $\alpha_{\text {pro }}$ was assumed as the attenuation of the $\mathrm{LP}_{01}$ mode, because the attenuation of the $\mathrm{LP}_{11}$ mode with sufficiently thick $T_{c}$ and low $\mathrm{XT}$ is almost equal to that of the $\mathrm{LP}_{01}$ mode [40]. The $\alpha_{\mathrm{ex}}$ of core 8 was estimated to be $0.6 \mathrm{~dB} / \mathrm{km}$, which is smaller than the calculation shown in Fig. 13(a).

Fig. 17 shows the measured $\mathrm{XT}_{11-11}$ and $\mathrm{XT}_{01-01}$ at $1550 \mathrm{~nm}$. The fiber length was $11 \mathrm{~km}$, and the bending diameter was $310 \mathrm{~mm}$. XT $\mathrm{XT}_{01-01}$ was derived from linear extrapolation of the wavelength dependency of the measured XT over the singlemode region. The averaged $\mathrm{XT}_{01-01}$ and $\mathrm{XT}_{11-11}$ were -38.4 and $-5.5 \mathrm{~dB}$, respectively. The measured $\mathrm{XT}_{01-01}$ and $\mathrm{XT}_{11-11}$ were larger than the simulated values of -41.9 and $-10.5 \mathrm{~dB}$, respectively. These discrepancies arose from the difference between the ideal step profile used in the simulations and the actual profile.

Fig. 18 shows the measured near field pattern (NFP) of the 31-core fiber to confirm $\mathrm{LP}_{11}$-mode power transition from the central core (core 31 ) to the outer cores. Only core 31 was excited by the $\mathrm{LP}_{11}$ mode. The $\mathrm{LP}_{11}$-mode power in core 31

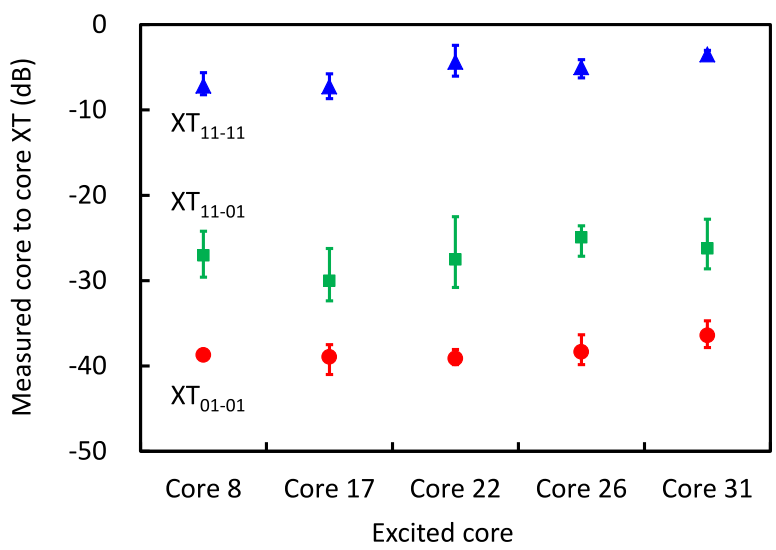

Fig. 17. Measured core-to-core $\mathrm{XT}$ at $1550 \mathrm{~nm}$ between $\mathrm{LP}_{11}$ modes ( $\mathrm{XT}_{11-11}$, blue triangle symbols), between $\mathrm{LP}_{01}$ modes $\left(\mathrm{XT}_{01-01}\right.$, red circle symbols), and between $\mathrm{LP}_{11}$ and $\mathrm{LP}_{01}\left(\mathrm{XT}_{11-01}\right.$, green square symbols). The bars indicate the maximum and minimum values among cores adjacent to the excited core.

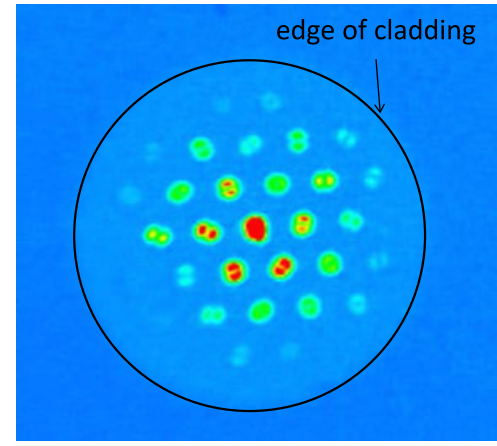

Fig. 18. Measured NFP of the fabricated 31-core fiber. Only the central core (core 31 ) was excited by the $\mathrm{LP}_{11}$ mode.

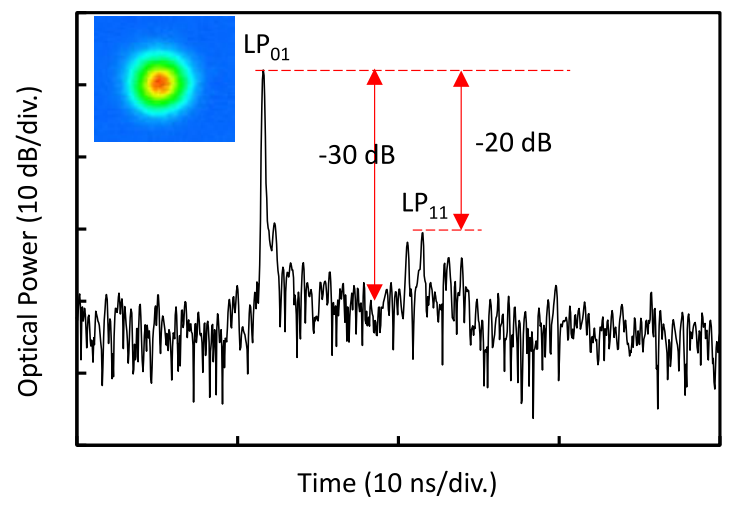

Fig. 19. Measured impulse response and NFP from a core in layer 2 of the 11-km fiber with an FI device. The inset shows a NFP after 11-km transmission.

was moved to neighboring cores owing to the large XT between the $\mathrm{LP}_{11}$ modes.

We confirmed $\mathrm{LP}_{11}$ suppression after $11-\mathrm{km}$ propagation. Fig. 19 shows the impulse-response signal of a core in layer 2 after 11-km transmission. An $\mathrm{LP}_{01}$-mode pulse was introduced to the fiber through a waveguide-type fan-in (FI) device [41]. The inter-mode XT through the fiber was smaller than $-30 \mathrm{~dB}$. The $\mathrm{LP}_{11}$ mode generated at a connection point of the FI and fiber was observed at the time predicted from the DMD of the 


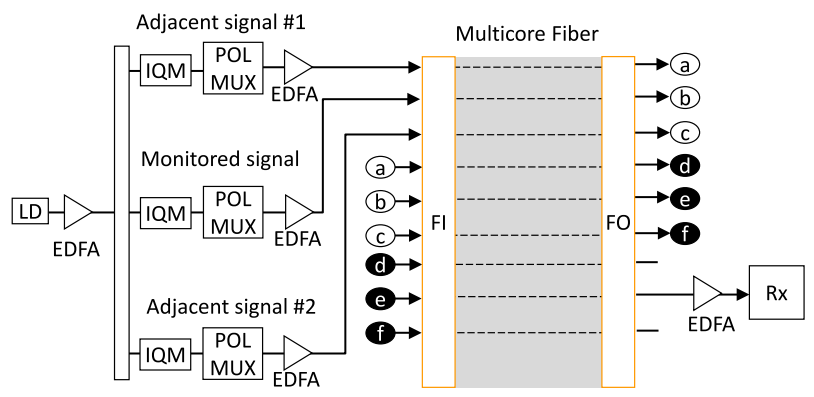

Fig. 20. Experimental set up for evaluating the transmission characteristics of MCFs.
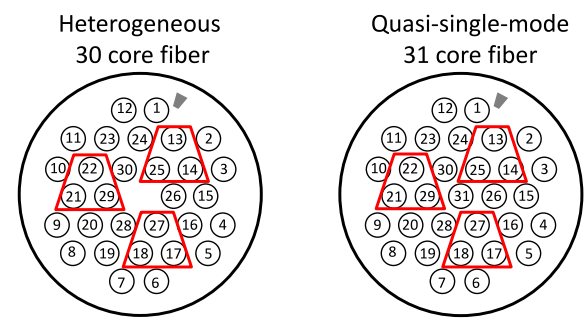

Monitored signal $\# 13 \rightarrow \# 17 \rightarrow \# 21$

Adjacent signals $\# 14 \rightarrow \# 18 \rightarrow \# 22$ $\# 25 \rightarrow \# 27 \rightarrow \# 29$

Fig. 21. Signal assignment for the transmission experiment on the 30-core and 31-core fibers.

$\mathrm{LP}_{11}$ mode to the $\mathrm{LP}_{01}$ mode. The power was $-20 \mathrm{~dB}$ less than that of the $\mathrm{LP}_{01}$ mode. We have concluded that the power of the received $L_{11}$ mode was sufficiently small after $11-\mathrm{km}$ propagation, which is also supported by a NFP from another end, as shown in the inset of Fig. 18.

\section{TRANSMISSION EXPERIMENTS}

We evaluated and compared the transmission characteristics of the heterogeneous 30-core fiber and the QSM 31-core fiber.

\section{A. Measurement Setup}

Fig. 20 shows the schematics of our measurement setup. Thee modulators were prepared. We used the signal from a modulator for monitoring the $Q$ value. The signals from other modulators were used as dummy signals to adjacent cores to evaluate the degradation of the $Q$ value due to XT from the adjacent cores. We prepared two kinds of modulators; polarization multiplexed QPSK and polarization multiplexed 16 QAM. The baud rate for both formats was 11.5 Gbaud. The signals were circulated three times through fan-in/fan-out (FI/FO) devices. The $Q$ value of the monitored signal after three-span propagation was monitored. The total transmission distance was $28.8 \mathrm{~km}(9.6 \mathrm{~km} \times 3)$ for the 30 -core fiber and $33 \mathrm{~km}(11 \mathrm{~km} \times 3)$ for the 31 -core fiber. Fig. 21 shows signal assignment for the 30-core and 31-core fibers.

Fig. 22 shows XT characteristics of the fibers with FI/FO devices. We employed FI/FO devices with a wave guide structure [41]. Table IV summarizes XT and attenuation at $1550 \mathrm{~nm}$ of three spans.

The back-to-back $Q$ value of the measurement setup was 9.0 $\mathrm{dB}$ for QPSK transmission and $10.2 \mathrm{~dB}$ for 16QAM transmission.

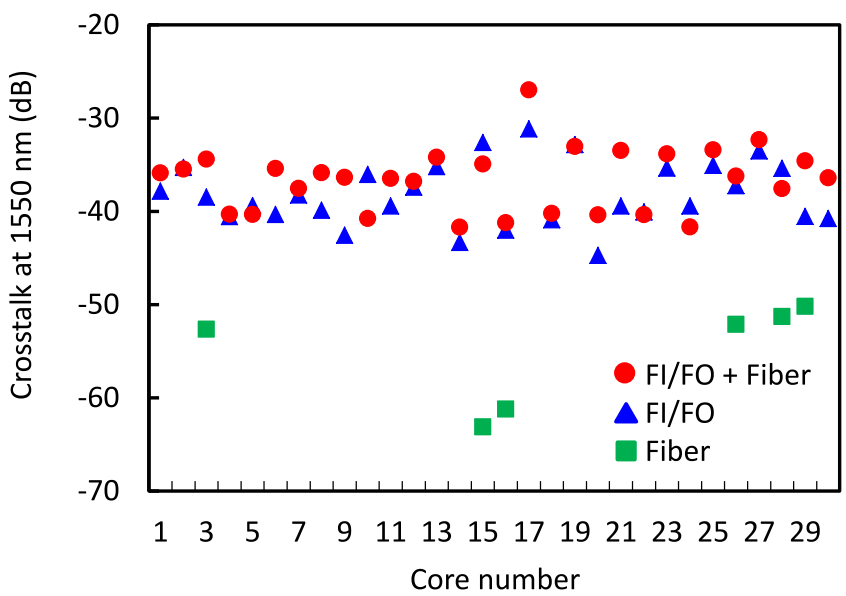

(a)

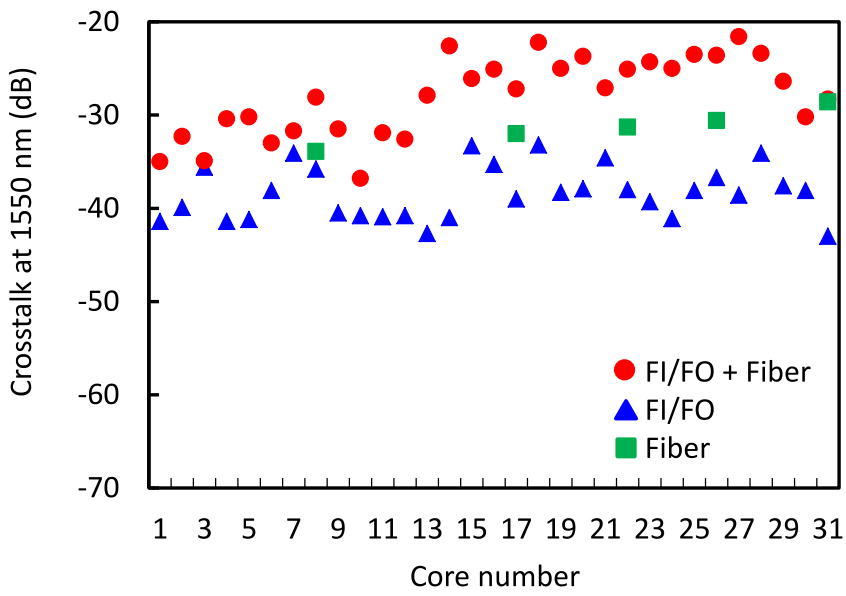

(b)

Fig. 22. Measured XT characteristics of the fiber, FI/FO, and FI/FO + Fiber: (a) Heterogeneous 30-core fiber. (b) QSM 31-core fiber.

TABLE IV

Three Span Characteristics OF High-CORE-COUNT MCF With FI/FOs

\begin{tabular}{lcc}
\hline \hline & Heterogeneous 30-core fiber & QSM 31-core fiber \\
\hline XT [dB] & -26.9 & -16.6 \\
Attenuation [dB] & 32.5 & 20.1 \\
\hline
\end{tabular}

\section{B. Transmission Characteristics}

In the case of QPSK transmission over the heterogeneous 30-core fiber, a small $Q$ penalty of $0.2 \mathrm{~dB}$ was observed for both one-core transmission and three-core transmission. The $Q$ penalty of 16 QAM was slightly larger than that of QPSK. However, $Q$ penalty was kept small for both $0.4 \mathrm{~dB}$ one-core transmission and $0.7 \mathrm{~dB}$ three-core transmission.

In contrast, degradation was observed for the $Q$ value over the QSM 31-core fiber. The $Q$ penalty of one-core transmission with QPSK was $0.4 \mathrm{~dB}$. However, the $Q$ penalty became $1.4 \mathrm{~dB}$ for three-core transmission. In the case of 16QAM, the $Q$ penalty was $1.7 \mathrm{~dB}$ even for one-core transmission. The $Q$ penalty for three-core transmission was $4.1 \mathrm{~dB}$. 

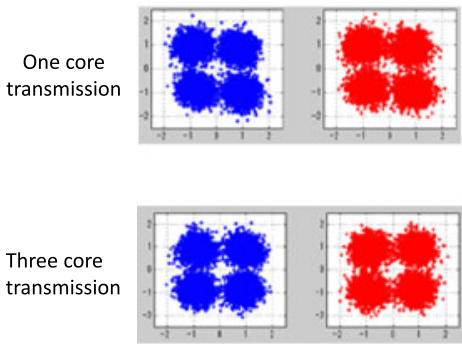

QPSK transmission
16QAM transmission
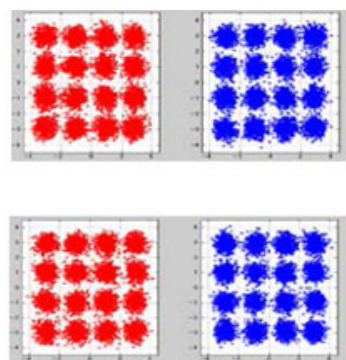

Fig. 23. Constellation map over a heterogeneous 30-core fiber with QPSK and 16 QAM for each polarization. Additional ASE noise was imposed to be visible the change of the constellation map.
QPSK transmission

One core transmission
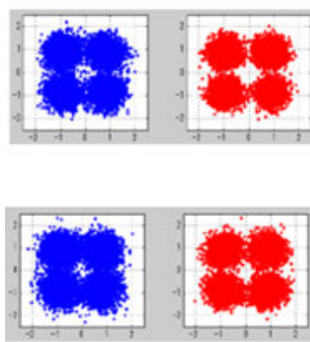

160AM transmission
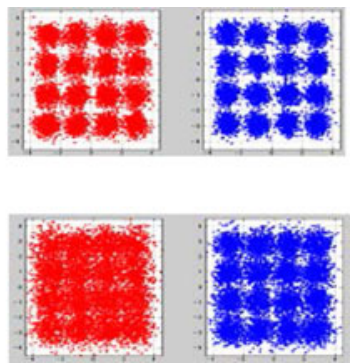

Fig. 24. Constellation map over a QSM 31-core fiber with QPSK and 16 QAM for each polarization. Additional ASE noise was imposed to be visible the change of the constellation map.

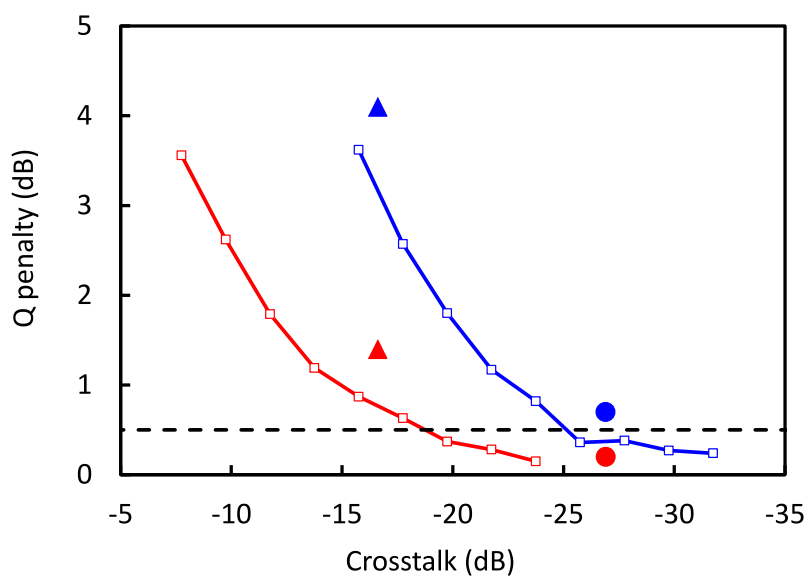

\begin{tabular}{|c|c|c|c|}
\hline & $\begin{array}{c}\text { Heterogeneous } \\
\text { 30-core fiber }\end{array}$ & $\begin{array}{c}\text { Quasi-Single-mode } \\
\text { 31-core fiber }\end{array}$ & $\begin{array}{c}\text { Homogeneous } \\
\text { 12-core fiber [37] }\end{array}$ \\
\hline QPSK & & $\Delta$ & $-\square-$ \\
\hline 16QAM & & $\Delta$ & $-\square-$ \\
\hline
\end{tabular}

Fig. 25. Measured $Q$ penalty as a function of XT. Circle symbols and triangle symbols indicate the measured $Q$ penalty for 30-core and 31-core fiber. Square symbols indicate the measured $Q$ penalty of our previous experiment on 12 -core fiber [39].

Figs. 23 and 24 show the measured constellation maps over the heterogeneous 30-core fiber and the QSM 31-core fiber, respectively. The ASE noise was added to make the $Q$-degradation tendency for fibers and modulation formats understandable. The constellation maps demonstrated the same tendency with the measured $Q$ value.

Fig. 25 shows the measured $Q$ penalty as a function of XT for different modulation formats. Circle and triangle symbols indicate the measured $Q$ penalty for 30- and 31-core fibers. Square symbols indicate measured $Q$ penalty for 12 -core fiber [37]. For the 12-core fiber, the required XT is less than $-18 \mathrm{~dB}$ for QPSK and less than $-25 \mathrm{~dB}$ for $16 \mathrm{QAM}$ when the allowable $Q$ penalty is $0.5 \mathrm{~dB}$. The measured $Q$ values of the heterogeneous 30 -core fiber are close to those of the 12-core fiber. However, an additional penalty was observed for the measured $Q$ values of the QSM 31-core fiber. Because the additional penalty will originate from the mode coupling during propagation and XT between cores, we need to suppress the higher-order mode propagation.

\section{CONCLUSION}

The development trend of MCFs for dense spatial division multiplexing was reviewed. Many kinds of MCFs have been proposed to overcome the tradeoff relationship among the SCC, cladding diameter, XT, and DMD.

The design concept and fabrication results of SM-MCFs with an SCC of larger than 30 was presented. A 30-core fiber with a heterogeneous core was realized with a low XT of $-55 \mathrm{~dB}$ and length of $9.6 \mathrm{~km}$ and a low $Q$ penalty for QPSK and 16 QAM. A 31-core fiber with the QSM recorded the highest SCC as an SM-MCF. The $Q$ penalty due to the XT was observed during the transmission experiment on the 31-core fiber. The characteristics will improve by suppressing the higher-order mode propagation.

\section{REFERENCES}

[1] H. Takara, A. Sano, T. Kobayashi, H. Kubota, H. Kawakami, A. Matsuura, Y. Miyamoto, Y. Abe, H. Ono, K. Shikama, Y. Goto, K. Tsujikawa, Y. Sasaki, I. Ishida, K. Takenaga, S. Matsuo, K. Saitoh, M. Koshiba, and T. Morioka, "1.01-Pb/s (12 SDM/222 WDM/456 Gb/s) crosstalk-managed transmission with $91.4-\mathrm{b} / \mathrm{s} / \mathrm{Hz}$ aggregate spectral efficiency," presented at the Eur. Conf. Exhib. Optical Communication, Amsterdam, The Netherlands, 2012, Paper Th.3.C.1.

[2] J. Sakaguchi, W. Klaus, B. J. Puttnam, J. M. D. Mendinueta, Y. Awaji, N. Wada, Y. Tsuchida, K. Maeda, M. Tadakuma, K. Imamura, R. Sugizaki, T. Kobayashi, Y. Tottori, M. Watanabe, and R. V. Jensenexa, "19-core MCF transmission system using EDFA with shared core pumping coupled via free-space optics," Opt. Exp., vol. 22, no. 1, pp. 90-95, Jan. 2014

[3] T. Kobayashi, H. Takara, A. Sano, T. Mizuno, H. Kawakami, Y. Miyamoto, K. Hiraga, Y. Abe, H. Ono, M. Wada, Y. Sasaki, I. Ishida, K. Takenaga, S. Matsuo, K. Saitoh, M. Yamada, H. Masuda, and T. Morioka, " $2 \times 344$ $\mathrm{Tb} / \mathrm{s}$ propagation-direction interleaved transmission over $1500-\mathrm{km} \mathrm{MCF}$ enhanced by multicarrier full electric-field digital back-propagation," presented at the Eur. Conf. Exhib. Optical Communication, London, U.K., 2013, Paper PD3.E.4.

[4] K. Igarashi, T. Tsuritani, I. Morita, Y. Tsuchida, K. Maeda, M. Tadakuma, T. Saito, K. Watanabe, K. Imamura, R. Sugizaki, and M. Suzuki, "Super-Nyquist-WDM transmission over 7,326-km Seven-core Fiber with Capacity-distance Product of 103 Exabit/s.km," Opt. Exp., vol. 22, no. 2, pp. 1220-1228, Jan. 2014.

[5] V. A. J. M. Sleiffer, Y. Jung, V. Veljanovski, R. G. H. van Uden, M. Kuschnerov, Q. Kang, L. Grüner-Nielsen, Y. Sun, D. J. Richardson, S. Alam, F. Plletti, J. K. Safu, A. Dhar, H. Chen, B. Inan, A. M. J. Koonen, B. Corbett, R. Winfield, A. D. Ellis, and H. de. Waardt, "73.7 $\mathrm{Tb} / \mathrm{s}(96 \times 3 \times 256-\mathrm{Gb} / \mathrm{s})$ mode-division-multiplexed DP-16QAM transmission with inline MM-EDFA," presented at the Eur. Conf. Exhib. Optical Communication, Amsterdam, The Netherlands, 2012, Paper Th.3.C.4.

[6] N. K. Fontaine, R. Ryf, H. Chen, A. V. Benitez, J. E. A. Lopez, R. A. Correa, B. Guan, B. Ercan, R. P. Scott, S. J. B. Yoo, L. Grüner-Nielsen, Y. Sun, and R. J. Lingle, " $30 \times 30$ MIMO transmission over 15 spatial 
modes," presented at the Optical Fiber Communication Conf., Los Angeles, CA, USA, 2015, Paper Th5C.1.

[7] T. Mizuno, T. Kobayashi, H. Takara, A. Sano, H. Kawakami, T. Nakagawa, Y. Miyamoto, Y. Abe, T. Goh, M. Oguma, T. Sakamoto, Y. Sasaki, I. Ishida, K. Takenaga, S. Matsuo, K. Saitoh, and T. Morioka, "12-core x 3-mode dense space division multiplexed transmission over $40 \mathrm{~km}$ employing multi-carrier signals with parallel MIMO equalization," presented at the Optical Fiber Communication Conf., San Francisco, CA, USA, 2014, Paper Th5B.2.

[8] K. Shibahara, T. Mizuno, H. Takara, A. Sano, H. Kawakami, D. Lee, Y. Miyamoto, H. Ono, M. Oguma, Y. Abe, K. Kobayashi, T. Matsui, R. Fukumoto, Y. Amma, T. Hosokawa, S. Matsuo, K. Saito, H. Nasu, and T. Morioka, "Dense SDM (12-core x 3-mode) transmission over $527 \mathrm{~km}$ with 33.2-ns mode-dispersion employing low-complexity parallel MIMO frequency-domain equalization," presented at the Optical Fiber Communication Conf., Los Angeles, CA, USA, 2015, Paper Th5C.3.

[9] J. Sakaguchi, W. Klaus, J.-M. D. Mendinueta, B. J. Puttnam, R. S. Luis, Y. Awaji, N. Wada, T. Hayashi, T. Nakanishi, T. Watanabe, Y. Kokubun, T. Takahata, and T. Kobayashi, "Realizing a 36-Core, 3-mode fiber with 108 spatial channels," presented at the Optical Fiber Communication Conf., Los Angeles, CA, USA, 2015, Paper Th5C.2.

[10] K. Igarashi, D. Souma, Y. Wakayama, K. Takeshima, Y. Kawaguchi, T. Tsuritani, I. Morita, and M. Suzuki, "114 space-division-multiplexed transmission over 9.8-km weakly-coupled-6-mode uncoupled-19-core fibers," presented at the Optical Fiber Communication Conf., Los Angeles, CA, USA, 2015, Paper Th5C.4.

[11] B. J. Puttnam, R. S. Luís, W. Klaus, J. Sakaguchi, J.-M. Delgrado Mendinueta, Y. Awaji, N. Wada, Y. Tamura, T. hayashi, M. Hirano, and J. Marciante, "2.15 Pbs/transmission using a core homogeneous singlemode multi-core fiber and wideband optical comb," presented at the Eur. Conf. Exhib. Optical Communication, Valencia, Spain, 2015, Paper PDP.3.1.

[12] D. Soma, K. Igarashi, Y. Wakayama, T. Takashima, Y. Kawaguhi, N. Yoshikane, T. Tsuritani, I. Morita, and M. Suzuki, "2.05 Peta-bit/s Super Nyquist-WDM transmission using 9.8-km 6-Mode 19-core fiber in full C band," presented at the Eur. Conf. Exhib. Optical Communication, Valencia, Spain, 2015, Paper PDP.3.2.

[13] R. Ryf, H. Chen, N. K. Fontaine, A. M. Velazquez-Benítez, J. AntonioLópez, C. Jin, H. Huang, M. Bigot-Astruc, D. Molin, F. Achten, P. Sillard, and R. Amezcua-Corea, "10-mode mode division-multiplexed transmission over 125-km single-span multimode fiber," presented at the Eur. Conf. Exhib. Optical Communication, Valencia, Spain, 2015, Paper PDP.3.3.

[14] Y. Amma, Y. Sasaki, K. Takenaga, S. Matsuo, J. Tu, K. Saitoh, M. Koshiba, T. Morioka, and Y. Miyamoto, "High-density multicore fiber with heterogeneous core arrangement," presented at the Optical Fiber Communication Conf., Los Angeles, CA, USA, 2015, Paper Th4C.4.

[15] Y. Sasaki, S. Saitoh, Y. Amma, K. Takenaga, S. Matsuo, K. Saitoh, T. Morioka, and Y. Miyamoto, "Quasi-single-mode homogeneous 31core fiber," presented at the Eur. Conf. Exhib. Optical Communication, Valencia, Spain, 2015, Paper We.1.4.4.

[16] P. Sillard, D. Molin, B. Bigot-Astruc, A. Amezcua-Correa, K. De Jongh, and F. Achten, " $50 \mu \mathrm{m}$ multimode fibers for mode division multiplexing," presented at the Eur. Conf. Exhib. Optical Communication, Valencia, Spain, 2015, Paper Mo.4.1.2.

[17] T. Sakamoto, T. Matsui, K. Saitoh, S. Saitoh, K. Takenaga, S. Matsuo, Y. Tobita, N. Hanzawa, K. Nakajima, and F. Yamamoto, "Few-mode multicore fiber with highest core multiplicity factor," presented at the Eur. Conf. Exhib. Optical Communication, Valencia, Spain, 2015, Paper We.1.4.3.

[18] S. Matsuo, K. Takenaga, K. Saitoh, K. Nakajima, Y. Miyamoto, and T. Morioka, "High-spatial-multiplicity multi-core fibres for future densespace-division-multiplexing system," presented at the Eur. Conf. Exhib. Optical Communication, Valencia, Spain, 2015, Paper Th.1.2.1.

[19] S. Matsuo, K. Takenaga, Y. Arakawa, Y. Sasaki, S. Taniagwa, K. Saitoh, and M. Koshiba, "Large-effective-area ten-core fiber with cladding diameter of about $200 \mu \mathrm{m}$," Opt. Lett., vol. 36, no. 23, pp. 4626-4628, Dec. 2011.

[20] D. Marcuse, "Loss analysis of single-mode fiber splices," Bell Syst. Tech. J., vol. 56, no. 5, pp. 703-718, May 1977.

[21] Y. Amma, A. Takahashi, K. Takenaga, and S. Matsuo, "Accuracy of core alignment with end-view function for multicore fiber," presented at the IEEE Photonics Society Summer Topical Meeting Ser., Montreal, QC, Canada, Jul. 2014, Paper TuE2.4,.

[22] K. Yoshida, A. Takahashi, T. Konuma, K. Yoshida, and S. Sasaki. (2012, Jan.). Fusion splicer for specialty optical fiber with advanced functions.
Fujikura Tech. Rev. [Online]. 41, pp. 10-13. Available: http://www. fujikura.co.jp/eng/rd/gihou/backnumber/pages/2036771_4995.html

[23] T. Sakamoto, T. Mori, T. Yamamoto, M. Wada, and F. Yamamoto, "Moderately coupled $125-\mu$ m cladding 2 LP-mode 6 -core fiber for realizing low MIMO-DSP and high spatial density," presented at the Eur. Conf. Exhib. Optical Communication, Cannes, France, 2015, Paper Tu.4.1.3.

[24] P. Winzer, A. Gnauck, A. Konczykowska, F. Jorge, and J.-Y. Dupuy, "Penalties from in-band crosstalk for advanced optical modulation formats," presented at the 37th Eur. Conf. Expo. Optical Communications, Geneva, Switzerland, Paper Tu.5.B.7.

[25] K. Takenaga, Y. Sasaki, N. Guan, S. Matsuo, M. Kasahara, K. Saitoh, and M. Koshiba, "Large effective-area few-mode multicore fiber," Opt. Lett., vol. 24, no. 21, pp. 1941-1944, Nov. 1, 2012.

[26] K. Saitoh, M. Koshiba, K. Takenaga, and S. Matsuo, "Crosstalk and core density in uncoupled multicore fiber," IEEE Photon. Technol. Lett., vol. 24, no. 21, pp. 1898-1901, Nov. 1, 2012.

[27] T. Mori, T. Sakamoto, M. Wada, T. Yamamoto, and F. Yamamoto, "Fewmode fibers supporting more than two lp modes for mode-divisionmultiplexed transmission with MIMO DSP," J. Lightw. Technol., vol. 32, no. 14, pp. 2468-2479, Jul. 2014.

[28] T. Sakamoto, T. Mori, T. Yamamoto, and S. Tomita, "Differential mode delay managed transmission line for WDM-MIMO system using multistep index fiber," J Lightw. Technol., vol. 30, no. 17, pp. 2783-2787, Jul. 2012.

[29] K. Saioth and S. Matsuo, "Multicore fiber technology," J. Lightw. Technol., vol. 36, no. 4, Feb. 2016, early access, doi:10.1109/JLT.2015.2466444

[30] M. Koshiba, K. Saitoh, and Y. Kokubun, "Heterogeneous multi-core fibers: Proposal and design principle," IEICE Electron. Exp., vol. 6, no. 2, pp. 98-103, Jan. 2009.

[31] T. Hayashi, T. Taru, O. Shimakawa, T. Sasaki, and E. Sasaoka, "Design and fabrication of ultra-lows crosstalk and low-loss multi-core fiber," Opt. Exp., vol. 19, no. 17, pp. 16576-16592, Aug. 2011.

[32] M. Koshiba, K. Saitoh, K. Takenaga, and S. Matsuo, "Analytical expression of average power-coupling coefficients for estimating intercore crosstalk in multicore fibers," Photon. J., vol. 4, no. 5, pp. 1987-1995, Oct. 2012.

[33] K. Saitoh, M. Koshiba, K. Takenaga, and S. Matsuo, "Low-crosstalk multicore fibers for long-haul transmission," presented at the Photonics West, San Francisco, CA, USA, 2012, vol. 8284, pp. 828401-1-828401-8.

[34] Y. Sasaki, Y. Amma, K. Takenaga, S. Matsuo, K. Saitoh, and M. Koshiba, "Investigation of crosstalk dependencies on bending radius of heterogeneous multicore fiber," presented at the Optical Fiber Communication Conf./ Nat. Fiber Optic Engineers Conf., Anaheim, CA, USA, 2013, Paper OTh $3 \mathrm{~K} .3$

[35] K. Takenaga, Y. Arakawa, Y. Sasaki, S. Tanigawa, S. Matsuo, K. Saitoh, and M. Koshiba, "A large effective area multi-core fiber with an optimized cladding thickness," Opt. Exp., vol. 19, no. 26, pp. B543-B550, Dec. 2011.

[36] T. Hayashi, T. Taru, O. Shimakawa, T. Sasaki, and E. Sasaoka, "Characterization of crosstalk in ultra-low-crosstalk multi-core fiber," J. Lightw. Technol., vol. 30, no. 4, pp. 583-589, Feb. 2012.

[37] F. Yaman, S. Zhang, Y. Huang, E. Ip, J. D. Downie, W. A. Wood, A. Zahkharian, S. K. Mishra, J. E. Hurley, Y. Zhang, I. B. Djordjevic, M. Huang, E. Ateo, K. Nakamura, T. Inoue, Y. Inada, and T. Ogata, "First quasi-single-mode transmission over transoceanic distance using few-mode fibers," presented at the Optical Fiber Communication Conf., Los Angeles, CA, USA, 2015, Paper Th5C.7.

[38] Q. Sui, H. Zhang, J. D. Downie, W. A. Wood, J. Hurley, S. Mishra, A. P. T. Lau, C. Lu, H. Tam, and P. K. A. Wai, "Long-haul quasi-single-mode transmissions using few-mode fiber in presence of multi-path interference," Opt. Exp., vol. 23, no. 3, pp. 3156-3169, Feb. 2015.

[39] A. Sano, H. Takara, T. Kobayashi, and Y. Miyamoto, "Crosstalk-managed high capacity long haul multicore fiber transmission with propagationdirection interleaving," J. Lightw. Technol., vol. 32, no. 16, pp. 2771-2779, Aug. 2014.

[40] Y. Sasaki, Y. Amma, K. Takenaga, S. Matsuo, K. Saitoh, and M. Koshiba, "Few-mode multicore fiber with 36 spatial modes (three modes $\left(\mathrm{LP}_{01}, \mathrm{LP}_{11 \mathrm{a}}, \mathrm{LP}_{11 \mathrm{~b}}\right) \times 12$ Cores)," J. Lightw. Technol., vol. 33, no. 5, pp. 964-970, Mar. 2015.

[41] R. R. Thomson, H. T. Bookey, N. D. Psaila, A. Fender, S. Campbell, W. N. MacPherson, J. S. Barton, D. T. Reid, and A. K. Kar, "Ultrafastlaser inscription of a three dimensional fan-out device for multicore fiber coupling applications," Opt. Exp., vol. 15, no. 18, pp. 11691-11697, Sep. 2007. 
Shoichiro Matsuo (M'11) was born in Fukuoka, Japan, in 1964. He received the B.E. and M.E. degrees in electrical engineering from Kyushu University, Fukuoka, Japan, in 1988 and 1990, and the Ph.D. degree in production and information science from Utsunomiya University, Tochigi, Japan, in 2008, respectively.

He has been with Fujikura, Ltd., Chiba, Japan, since 1990, focusing on the research and development of transmission fibers for long-haul networks and FTTH networks as well as rare-earth-doped fibers and photonic bandgap fibers, and the manufacturing technology for these optical fibers. He was the General Manager of Laboratory, Fujikura, Ltd., from April 2013 to October 2015. He is currently the General Manager of both the Optical Fiber Development Department and the Suzuka Optical Fiber Production Department, Fujikura Ltd.

Dr. Matsuo is a Member of the Optical Society of America, the Japanese Society of Applied Physics, and the Institute of Electronics, Information and Communication Engineers.

Katsuhiro Takenaga was born in Tochigi, Japan, in 1976. He received the B.S. degree from Shinshu University, Nagano, Japan, and the M.S. degree from Hokkaido University, Sapporo, Japan, in 1999 and 2001, both in physics.

In 2001, he joined Fujikura, Ltd., Chiba, Japan, where he has been involved in research and development of optical fibers. He is a Member of the Institute of Electronics, Information and Communication Engineers of Japan.

Yusuke Sasaki was born in Chiba, Japan, in 1986. He received the B.E. and M.E. degrees in electrical engineering from the Tokyo Institute of Technology, Tokyo, Japan, in 2008 and 2010, respectively.

Since 2010, he has been with the Optics and Electronics Laboratory, Fujikura, Ltd., Chiba, where he has been involved in research and development of multicore fibers. He is a Member of the Institute of Electronics, Information and Communication Engineers of Japan.

Yoshimichi Amma received the B.S. degree in 2010 and M.S. degree in mechanical engineering from Yokohama National University, Kanagawa, Japan, in 2012.

He joined the Optical Fibre Technology Department, Optics and Electronics Laboratory, Fujikura, Ltd., Chiba, Japan, in 2012. He has three years of experience in research and development of multicore fibers, and he has attended six conferences.

Mr. Amma is a Member of the Institute of Electronics, Information and Communication Engineers of Japan.

Shota Saito was born in Hokkaido, Japan, in 1990. He received the B.S. degree in engineering and the M.S. degree in media and network technologies from Hokkaido University, Sapporo, Japan, in 2012 and 2014, respectively.

He has been at Fujikura, Ltd., Chiba, Japan, since 2014 and has been working on research and development of multicore fibers.

Mr. Saito is a Member of the Institute of Electronics, Information and Communication Engineers of Japan.

Kunimasa Saitoh (S'00-M'01) received the B.S., M.S., and Ph.D. degrees in electronic engineering from Hokkaido University, Sapporo, Japan, in 1997, 1999, and 2001, respectively.

From 1999 to 2001, he was a Research Fellow of the Japan Society for the Promotion of Science. From 2001 to 2005, he was a Research Associate with the Graduate School of Engineering, Hokkaido University. From 2005 to 2013, he was an Associate Professor with the Graduate School of Information Science and Technology, Hokkaido University, and in 2013, he became a Professor there. He has been involved in research on fiber optics, nanophotonics, integrated optical devices, and computer-aided design and modeling of guided-wave devices. $\mathrm{He}$ has authored more than 160 research papers in refereed international journals and 200 refereed conference presentations.

Dr. Saitoh is a Member of the Optical Society of America, and the Institute of Electronics, Information and Communication Engineers (IEICE). He received the Excellent Paper Award and the Young Scientist Award from the IEICE, in 1999 and 2002, respectively, the Young Scientists' Prize of the Commendation for Science and Technology from the Ministry of Education, Culture, Sports, Science, and Technology, Government of Japan, in 2008. From 2009 to 2010, he served as a Secretary/Treasurer of the IEEE Sapporo Section.
Takashi Matsui, biography not available at the time of publication.

Kazuhide Nakajima, biography not available at the time of publication.

Takayuki Mizuno (M'04) received the B.E. degree in applied physics, the M.E. degree in crystalline materials science, and the Dr. Eng. degree in quantum engineering from Nagoya University, Nagoya, Japan, in 1998, 2000, and 2007 respectively.

In 2000, he joined NTT Photonics Laboratories, NTT Corporation, Tokyo, Japan, where he was involved in research and development of silica planar lightwave circuit optical waveguide devices, including arrayed-waveguide gratings, Mach-Zehnder interferometer-based filters and switches, and digital coherent demodulators for advanced modulation formats. He is currently a Senior Research Engineer at NTT Network Innovation Laboratories, NTT Corporation, Kanagawa, Japan. He is the author and/or coauthor of more than 80 journal and international conference papers, and holds more than 30 granted patents His present research interests include space-division multiplexed transmission technology for ultrahigh capacity optical transport systems.

Dr. Mizuno is a Member of the Institute of Electronics, Information, and Communication Engineers of Japan.

Hidehiko Takara received the B.S., M.E., and Ph.D. degrees in electrical engineering from the University of Keio, Kanagawa, Japan, in 1986, 1988, and 1997 , respectively.

In 1988, he joined NTT Corporation, Kanagawa, Japan. Since then, he has been involved in research on ultrahigh-speed/large capacity optical transmission systems and optical measurement techniques. He is currently a Professor at the Okinawa National College of Technology, Nago, Japan. He is a Member of the Institute of Electronics, Information and Communication Engineers.

Yutaka Miyamoto, biography not available at the time of publication.

Toshio Morioka was born in Hyogo, Japan. He received the B.E. degree in applied physics from Waseda University, Tokyo, Japan, in 1982, the M.S. degree in optical sciences from the Optical Sciences Center, University of Arizona, Tucson, AZ, USA, in 1984, and the M.S. and Ph.D. degrees in physics and applied physics from Waseda University in 1985 and 1995, respectively. He joined the Yokosuka Electrical Communication Laboratory of Nippon Telegraph and Telephone Corporation (NTT) in 1985. From 1996 to 1999, he was with NTT Bureau de Genève, Switzerland. In 2011, he moved to DTU Fotonik, Kgs. Lyngby, Denmark, and has been a Full Professor since 2013. Since 1985, he has been involved in various pioneering research programs on ultrafast and ultrahigh capacity transmission technologies. In 1987, he demonstrated the first ultrafast all-optical demultiplexing of optical time-division multiplexing signals, which led to the first one Tbit/s transmission experiment in 1996. In 1993, he also initiated research on supercontinuum sources for ultrahigh capacity wavelength-division multiplexing systems. In 2008, he organized the EXtremely Advanced Transmission Initiative in Japan, to initiate space-division multiplexing research based on novel fibers (multicore/few-mode fibers) aiming at well over Pbit/s transmission, which led to the first one Pbit/s transmission experiment in 2012.

He received the IEE Electronics Letters Premium Award in 1997 for his first Tbit/s optical transmission. He is a Fellow of the Optical Society of America (OSA) and the Institute of Electronics, Information and Communication Engineers (IEICE) of Japan and a Member of the IEEE Photonics Society/Communications Society. He was a Program and General Cochair of the OSA Topical meeting on Nonlinear Guided Waves and Their Applications in 1995 and 1996, respectively. He served as the Editor-in-Chief of the IEICE Transactions on Communications in 2005-2006. He holds 60 granted patents. 